\title{
Which tree species and biome types are most vulnerable to climate change in the U.S. Northern Rocky Mountains?
}

\author{
Authors: Andrew J. Hansen \& Linda B. Phillips
}

NOTICE: this is the author's version of a work that was accepted for publication in Forest Ecology and Management. Changes resulting from the publishing process, such as peer review, editing, corrections, structural formatting, and other quality control mechanisms may not be reflected in this document. Changes may have been made to this work since it was submitted for publication. A definitive version was subsequently published in Forest Ecology and Management, Volume 338, February 15, 2015. DOI\#10.1016/j.foreco.2014.11.008 Forest Ecology and Management

Hansen, Andrew J., and Linda B. Phillips. Which tree species and biome types are most vulnerable to climate change in the US Northern Rocky Mountains?. Forest Ecology and Management. February 2015. Pages 68-83. https://dx.doi.org/10.1016/j.foreco.2014.11.008

Made available through Montana State University's ScholarWorks scholarworks. montana.edu 


\title{
Which tree species and biome types are most vulnerable to climate change in the U.S. Northern Rocky Mountains?
}

\author{
Andrew J. Hansen \& Linda B. Phillips: Department of Ecology, Montana State University, Bozeman, MT
}

\begin{abstract}
The goal of this study was to assess components of vulnerability of tree species and biome types to pro-jected future climate within the Great Northern Landscape Conservation Cooperative (GNLCC) in the US Northern Rockies and the ecosystems surrounding Glacier and Yellowstone/Grand Teton National Parks. We drew on the results of five published studies and analyzed current and projected future climate suit-ability for 11 tree species and 8 biome types under two IPCC emissions scenarios. We assessed compo-nents of vulnerability based on four metrics of current and projected future climate suitability. Results for biome types indicated largely a shift from climates suitable for alpine and subalpine conifer to cli-mates suitable for desert scrub and grassland types. Results from the four studies of tree species indicated substantial loss of area of climate suitability for the four subalpine species by 2100 . This was especially true for Whitebark pine (Pinus albicaulis). Suitable climate for this species dropped from just over $20 \%$ of the study area in the reference period to $0.5-$ $7.0 \%$ by $2070-2100$ under the A2 scenario. The studies agreed in projecting expansion of climate suitability for some montane tree species but disagreed on expansion of climate suitability of westside mesic tree species to eastside locations such as Yellowstone National park. Importantly, the rankings of tree species vulnerability were similar among studies, scenar-ios, and geographic areas and indicated highest vulnerability for Whitebark pine and Mountain hemlock (Tsuga mertensiana). The results should help federal managers in the GNLCC prioritize tree species for cli-mate adaptation strategies. Moreover, our methods for using published data as a basis for climate vulnerability assessment can be applied within other LCCs across the US and other management units internationally.
\end{abstract}

\section{Introduction}

Federal land managers are increasingly concerned about how climate change affects natural resources and ecosystem services within their jurisdictions. The rates and ecological impacts of climate change over past decades are known to vary geographically across the United States (Karl et al., 2009). Climate warming and drying have been particularly pronounced within western states, resulting in increased frequency of severe fires, widespread forest pest outbreaks, and drought-induced forest mortality (Westerling et al., 2006; Allen et al., 2010). These factors in combination have led to large scale forest die-off especially in the southwestern deserts, the Rocky Mountains, and the Sierra Nevada (Breshears et al., 2005) and include keystone tree species such as Whitebark pine (Pinus albicaulis) ( Logan et al., 2010) and Joshua tree (Yucca brevifolia) ( Cole et al., 2011). In the coming decades, climate is expected to warm substantially across the western US, and is pro-jected to expand the area suitable for some tree species but cause dramatic declines in climate suitability for other species (McKinney et al., 2011; Coops and Waring, 2011; Gray and Hamann, 2013; Bell et al., 2014). Understanding forest response to climate change within local and regional management jurisdic-tions is vital to designing locally relevant strategies to cope with pending changes.

Resource managers can best plan, orient research, and manage if they are able to anticipate which species and ecosystems are most vulnerable to possible future change (Colwell et al., 2012; Stein et al., 2014). Accordingly, the US Department of Interior (DOI) launched programs aimed at assessing and managing vulnerable species under climate change (U.S. Department of the Interior, 2009). Among these programs, Landscape Conservation Cooperatives (LCCs) aim to communicate climate science among federal agencies within ecologically similar regions and to devise adaptation strategies for best coping with projected future change. These efforts are guided by recently published conceptual 
frameworks for linking science and management for climate change adaptation (National Park Service, 2010). Glick et al. (2011) and Stein et al. (2014), for example, advocate that vulnerability assessments be done to determine which elements are most at risk so that management actions can be focused on these elements.

An increasing number of studies have projected the potential impacts of future climate change on plant species and communities. One approach, termed bioclimate envelope modeling, quantifies the climate conditions where a species is currently present and projects the locations of these climate conditions under future scenarios (Huntley et al., 1995; Guisan and Thuiller, 2005; Berry et al., 2002; Pearson and Dawson, 2003; Thomas et al., 2004; Thuiller et al., 2005; Beale et al., 2008; Loarie et al., 2008; Serra-Diaz et al., 2013). This approach describes the conditions under which populations of a species persist in the presence of other biota as well as climatic constraints. Possible future distributions are projected on the assumption that current envelopes reflect species' environmental preferences, which will be retained under climate change. While this approach does not necessarily predict where a species will occur in the future (Pearson and Dawson, 2003; Thomas et al., 2004), it does project one foundational filter of where a species could exist in the future: climate suitability (Thuiller et al., 2005; Serra-Diaz et al., 2013). Consequently, bioclimate envelope modeling approaches have been widely used to assess change in the location of suitable climates for species under future climate scenarios.

We suggest that published bioclimate envelope studies of vegetation can serve as valuable contributions to the climate vulnerability assessments envisioned for DOI lands (Whittington et al., 2014). These studies are often done across sub-continental or larger areas, spatial extents much larger than LCCs or individual management jurisdictions. By analyzing results of these studies for the geographic areas of interest to managers, local patterns in current and projected future climate suitability can be revealed and used to craft management-relevant vulnerability assessments.

Synthesis of published studies of vegetation response to climate change can provide information both on which plant species and communities may have high potential impact under climate change, and the level of uncertainty in projected impacts based on level of agreement among studies. Vulnerability under climate change has been quantified based on area of suitable habitat in the current period and projected contraction, expansion, or shift in location of suitable habitat under future climate projections (Thomas et al., 2004; Thuiller et al., 2005; Loarie et al., 2008). Distance from current to newly suitable habitats is also considered because the pace of climate change may be faster than rates of population expansion to newly suitable habitats (Clark et al., 2003; Iverson et al., 2004; Zhu et al., 2012). In addition to changes in climate suitability, vulnerability assessments sometimes also include demographic, life history, and genetic factors (Thomas et al., 2011; Fordham et al., 2012; Pearson et al., 2014; Rehfeldt et al., 2014). We suggest, however, that consideration of climate suitability is an appropriate starting point for climate adaptation planning because knowledge of climate suitability is a critical filter for deciding where to use management actions to protect, restore, or establish species populations under climate change.

An assessment of vulnerability of vegetation to climate change is especially needed in the northern Rocky Mountains of the US. This region is within the Great Northern LCC, one of the first LCCs funded and a leader in building capacity for climate adaptation planning (http://greatnorthernlcc.org/). The Northern Rockies include the largest wilderness ecosystems in the 48 contiguous states, largely within and surrounding the iconic national parks of Yellowstone and Glacier (Baron, 2002). The harsh continental and montane climate strongly limits many species and the sharp gradients in climate imposed by topographic variability makes these relationships complex. Climate warming has been relatively rapid in this region over the past century (Karl et al., 2009) and is thought to have contributed to forest pest outbreaks and forest mortality in subalpine species such as Whitebark pine (Logan et al., 2010). Land allocation across the region is a mix of private and public lands with various levels of management flexibility or constraint. While there are few restrictions on management treatments on most private lands, human intervention in the form of active management is either dissuaded or illegal in national parks, roadless areas, and wilderness areas and management strategies need to be designed accordingly. In recent years, various studies have projected vegetation response to possible future climate change across western North America (see Table 1 for references). These studies generally project reductions in climate suitability for subalpine forests and expansion of grassland and shrubland communities in the coming century. The results of these studies have not been analyzed, however, within administrative units such as the GNLCC within which collaborative interagency management is being organized.

The goal of this paper was to assess components of vulnerability of tree species and biome types to projected future climate within the GNLCC and the ecosystems surrounding Glacier and Yellowstone/Grand Teton National Parks based on climate suitability. We do so using the projections of published studies of vegetation climate suitability under climate change across western North America. The results are expected to be useful for climate vulnerability assessments that the National Park Service is initiating (Whittington et al., 2014) and provide guidance to federal managers who are beginning to gauge the effectiveness of current management approaches under future climate change (GYCC, 2011). Beyond relevance to the GNLCC, this paper provides methods for harnessing existing bioclimate envelope studies to assess vulnerability within other LCCs across the US and other management units internationally.

\section{Methods}

\subsection{Overview}

We selected studies for inclusion in this synthesis that had projected tree or biome response to IPCC climate scenarios (IPCC, $2001,2007)$ in the western U.S. at a resolution of $5 \mathrm{~km}$ or finer using methods based on the climate characteristics of field samples of vegetation. Uncertainty in the projections of bioclimate envelope studies includes that due to assumptions about future climate (e.g. climate scenario), global climate models (GCMs) used to project the climate scenario, and methods used to develop the bioclimate envelop models. In analyzing the results of the selected studies, we controlled to the extent possible for climate scenario and GCMs used, thus focusing on the extent of agreement among study results despite differences in statistical methods among them. Three of the selected studies allowed us to report results separately for the IPCC SRES A2 scenario (relatively high greenhouse gas emissions) and the B1 scenario (lowest emissions). The studies differed in some extent in GCMs used. One study used a single GCM, three other studies reported either individual results for multiple GCMS or a consensus result among several GCMS. We summarized the projections for each study, scenario, and tree species or biome type in terms of modeled climate suitability during the current period and for three future periods to 2090. The results were used to rank the vulnerability of tree species to future climate change. The vulnerability ranking was done separately for the results of each study and then ranks were averaged among studies. This allowed us to evaluate the extent to which the vulnerability rankings were robust to the differences in GCMs 
Table 1

Attributes of studies included in this synthesis.

\begin{tabular}{|c|c|c|c|c|c|c|}
\hline Study & $\begin{array}{l}\text { Statistical } \\
\text { modeling } \\
\text { method }\end{array}$ & $\begin{array}{l}\text { Field data } \\
\text { sources }\end{array}$ & $\begin{array}{l}\text { Climate } \\
\text { data }\end{array}$ & $\begin{array}{l}\text { Reference and } \\
\text { future } \\
\text { projection periods }\end{array}$ & Scenarios/GCMs & $\begin{array}{l}\text { Vegetation } \\
\text { units }\end{array}$ \\
\hline Crookson et al. (2010) & Random forests & FIA & $\begin{array}{l}\text { Spline climate } \\
\text { surfaces } \\
\text { Rehfeldt (2006) }\end{array}$ & $\begin{array}{l}1961-1990 \\
2010 \\
2030 \\
2060 \\
2090\end{array}$ & $\begin{array}{l}\text { A2, B1/CGCM3, GFDLCM21, } \\
\text { HADCM3 }\end{array}$ & Tree species \\
\hline Coops and Waring (2011) & $\begin{array}{l}\text { Decision tree } \\
\text { regression }\end{array}$ & FIA & $\begin{array}{l}\text { PRISM (scaled to limits } \\
\text { on tree growth rates) }\end{array}$ & $\begin{array}{l}1950-1975 \\
1975-2006 \\
2020 \\
2050 \\
2080\end{array}$ & $\mathrm{~A} 2, \mathrm{~B} 1 / \mathrm{CGCM} 3$ & Tree species \\
\hline Gray and Hamann (2013) & Random forests & FIA & PRISM & $\begin{array}{l}\text { 1961-1990 } \\
2020 s \text { 2050s } \\
2080 s\end{array}$ & $\begin{array}{l}\text { Consensus of AIFI, A2, B1, B2 } \\
\text { under CGCM, CSIRO2, HADCM3, } \\
\text { ECHAM4, PCM }\end{array}$ & Tree species \\
\hline Bell et al. (2014) & $\begin{array}{l}\text { Baysian logistic } \\
\text { regression }\end{array}$ & FIA & PRISM & $\begin{array}{l}1981-2010 \\
2070-2099\end{array}$ & A2, B1/Average of $16 \mathrm{GCMs}^{\mathrm{a}}$ & Tree species \\
\hline Rehfeldt et al. (2012) & Random forests & $\begin{array}{l}\text { Brown } \\
(1994)\end{array}$ & $\begin{array}{l}\text { Spline climate } \\
\text { surfaces } \\
\text { Rehfeldt (2006) }\end{array}$ & $\begin{array}{l}1961-1990 \\
2010 \\
2030 \\
2060 \\
2090\end{array}$ & $\begin{array}{l}\text { A2, B1/Consensus of CGCM3, } \\
\text { GFDLCM21, HADCM3 }\end{array}$ & Biomes \\
\hline
\end{tabular}

a BCCR-BCM2.0, CGCM3.1(T47), CNRM-CM3, CSIRO-Mk3.0, GFDL-CM2.0, GFDL-CM2.1, GISS-ER, INM-CM3.0, IPSL-CM4, MIROC3.2, ECHO-G, ECHAM5/MPI-OM, MRICGCM2.3.2, CCSM3, PCM, UKMO-HadCM3.

and bioclimate modeling methods among studies. We summarize results for the full GNLCC study area and in and around the Yellowstone/Grand Teton (termed Greater Yellowstone) and Glacier National Parks. Because protected areas are often strongly influenced ecologically by surrounding lands, the actual units of analyses were the national parks and the surrounding Protected-Area Centered Ecosystems (PACEs) defined by Davis and Hansen (2011) based on contiguity of surrounding natural habitat, watershed boundaries, and extent of human edge effects. We report results of the studies for the GNLCC study area and point out where there was disagreement among studies, scenarios, or geographic locations.

\subsection{Study area}

The study area included the mountainous portion of the GNLCC within the U.S. (Fig. 1). This area is within the EPA Type II Western Cordillera Ecological Region and includes the EPA Type III Ecoregions Wyoming Basin, Wasatch and Uinta Mountains, Middle Rockies, Idaho Batholith, Northern Rockies, and Canadian Rockies within the states of Colorado, Utah, Wyoming, Montana, and Idaho (Wiken et al., 2011). The study area is centered on the north to south tending continental divide, which influences climate and vegetation patterns. While this region overall has a mid-latitude continental climate, the west side of the Rocky Mountains is moderated by a maritime influence, whereas the climate on the east side is harsher and more continental. In general, the higher elevations receive more precipitation and have lower average temperatures. Orographic lifting of air masses over the mountains forces much of the moisture content to precipitate (primarily as snow). Because of the mountainous terrain, local microclimates are highly variable as a result of differences in slope, aspect, exposure to prevailing wind, thermal inversions, and dry pockets. Climate likewise varies from north to south across latitude, with generally warmer and drier conditions to the south. Vegetation east of the continental divide grades from grass and shrublands in valley bottoms to open arid conifer forests, montane conifer forests, subalpine conifer forests, and alpine vegetation at the highest elevations. West of the continental divide, forest coverage is more continuous and mesic tree species such as western hemlock and western red cedar (see Table 2 for Latin names) are widespread. This area is 64.5\% federally owned and includes lands administered by the National Park Service, Forest Service, Bureau of Land Management, Fish and Wildlife Service and Department of Defense.

\subsection{Selection and traits of studies}

We searched the published literature using standard data bases (Web of Science, Google Scholar) for studies to include in this analysis. Criteria for selection were: the results projected future climate suitability for tree species or biomes across the study area; study results were comparable in GCM and scenarios; climate suitability was determined from vegetation samples collected in the field; grain size of analysis was $<=5 \mathrm{~km}$; and authors were willing to make results available to us. The resulting studies and their attributes are described in Table 1. Crookston et al. (2010), Coops and Waring (2011), Gray and Hamann (2013) and Bell et al. (2014) modeled climate suitability for tree species while Rehfeldt et al. (2012) modeled biome climate suitability. Hereafter, we refer to these studies as Crookston et al., Coops \& Waring, Gray \& Hamann, Bell et al., and Rehfeldt et al. All of the studies used climate niche modeling approaches to project locations with suitable climate under current climate and future climate scenarios. Field data on species presence came from the US Forest Service Forest Inventory and Analysis (FIA) database (http://fia.fs.fed.us) plots for all the studies of tree species and from Brown (1994) for the study of biome types by Rehfeldt et al. Climate data used by Crookston et al. and Rehfeldt et al. were derived through a spline climate surface approach by Rehfeldt (2006). Coops \& Waring, Gray \& Hamann and Bell et al. largely drew on climate data from PRISM (Daly et al., 2002). All of the studies except Coops \& Waring used absolute values of the climate variables as predictors in statistical climate suitability models. Coops and Waring used relative values for climate predictors that were scaled from 0 to 1 based on how much they limited tree growth in a mechanistic forest model (3PG). Statistical modeling methods used to derive the climate suitability functions differed among the studies as indicated in Table 1. All of these studies covered areas larger than our study 
area. All of the studies projected species or biome type "presence" or "absence" except Crookston et al. who reported a suitability index scaled from 0 to 1 . We used 0.5 as the cutoff value for presence in that study.

The future climate scenarios used by Crookston et al. and Rehfeldt et al. were from the IPCC Special Report Emissions Scenarios (SRES) Third Assessment Report (IPCC, 2001) and those used by Coops \& Waring, Gray \& Hamann, and Bell et al. were from IPCC SRES Fourth Assessment Report (IPCC, 2007). The climate projections for the Pacific Northwest for given GCMs were similar between the 2001 and 2007 versions (P. Mote, pers comm, 4/15/ 2014). The studies differed in the GCMs used to project future climate. Coops and Waring used only Canadian Center of Climate
Modeling and Analysis 3.0 (CGCM3). Crookston et al. reported results individually for CGCM3, Geophysical Fluid Dynamics Laboratory 2.1 (GFDLCM2.1), and Met Office Hadley Centre 3.0 (HADCM3). We averaged the vegetation viability scores among these GCM results for this analysis. Rehfeldt et al. reported the consensus of these three GCMs. Gray and Hamann provided the consensus results for $5 \mathrm{GCMs}$ and Bell et al. used the average of 16 GCMS (Table 1). All the studies ran the A2 and B1 SRES scenarios. Gray \& Hamann only reported the consensus among four scenarios (A2, B1, AIFI, B2), as did Rehfeldt et al. for A2 and B1. The A2 scenario assumes high greenhouse gas emissions, a regionally diverse world, and rapid economic growth and projects substantial global warming. The B1 scenario assumes relatively low emissions and

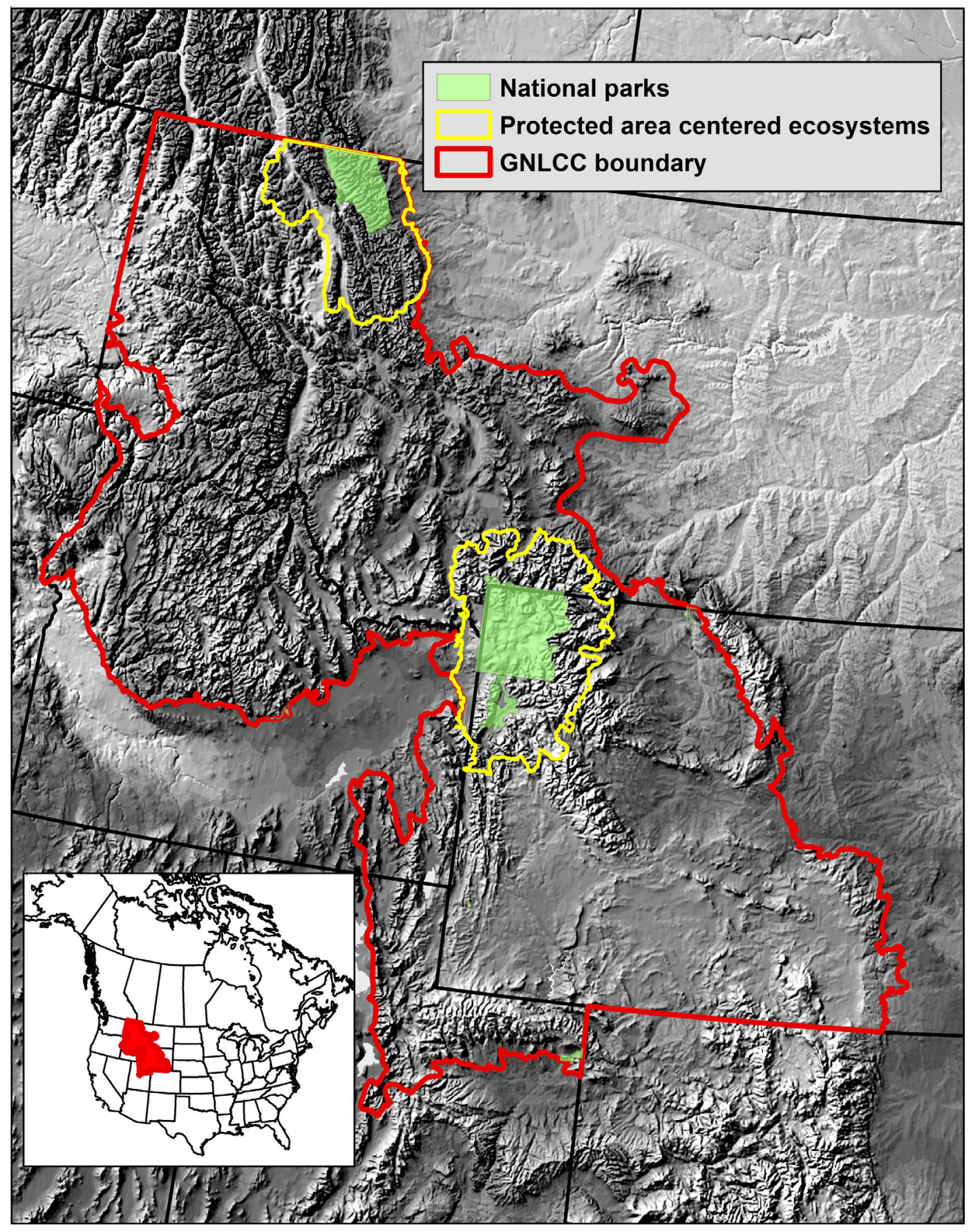

Fig. 1. Map of the study area. 
Table 2

Tree species modeled in each study or selected for this analysis.

\begin{tabular}{|c|c|c|c|c|c|}
\hline \multirow[t]{2}{*}{ Tree species } & \multirow[t]{2}{*}{ Guild } & \multicolumn{4}{|l|}{ Study } \\
\hline & & Crookston et al. (2010) & Coops and Waring (2011) & Gray and Hamann (2013) & Bell et al. (2014) \\
\hline Whitebark pine Pinus albicaulis & Subalpine & $\mathrm{X}$ & $\mathrm{X}$ & & \\
\hline Englemann spruce Picea engelmannii & Subalpine & $\mathrm{X}$ & $\mathrm{X}$ & $\mathrm{X}$ & $\mathrm{X}$ \\
\hline Subalpine fir Abies lasiocarpa & Subalpine & $\mathrm{X}$ & $\mathrm{X}$ & & $\mathrm{X}$ \\
\hline Lodgepole pine Pinus contorta & Subalpine & $\mathrm{X}$ & $\mathrm{X}$ & $\mathrm{X}$ & $\mathrm{X}$ \\
\hline Douglas-fir Pseudotsuga menziesii & Montane & $\mathrm{X}$ & $\mathrm{X}$ & $\mathrm{X}$ & \\
\hline Western larch Larix occidentalis & Montane & $\mathrm{X}$ & $\mathrm{X}$ & $\mathrm{X}$ & \\
\hline Grand fir Abies grandis & Montane & $\mathrm{X}$ & $\mathrm{X}$ & & \\
\hline Ponderosa pine Pinus ponderosa & Montane & $\mathrm{X}$ & $\mathrm{X}$ & $\mathrm{X}$ & $\mathrm{X}$ \\
\hline Mountain hemlock Tsuga mertensiana & Mesic & $\mathrm{X}$ & $\mathrm{X}$ & & \\
\hline Western hemlock Tsuga heterophylla & Mesic & $\mathrm{X}$ & $\mathrm{X}$ & $\mathrm{X}$ & \\
\hline Western redcedar Thuja plicata & Mesic & $\mathrm{X}$ & $\mathrm{X}$ & $\mathrm{X}$ & \\
\hline
\end{tabular}

global environmental sustainability and projects moderate global warming. A1F1 has higher emissions than A2 and B2 has lower emissions than B1. We analyzed results for both the A2 and B1 scenarios when studies reported them separately and the consensus results for the other studies. Climate projections of the IPCC changed relatively little between the SRES and more recent Coupled Model Intercomparison Project (Rogelj et al., 2012), thus the results of the studies reported here remain highly relevant to management.

\subsection{Tree species and biome types}

The tree species included in each study are listed in Table 2 . This list includes the dominant species within our study area. To facilitate interpretation of the results, we grouped these species into guilds based on coarse habitat associations. Subalpine species generally occur in cold environments above $2400 \mathrm{~m}$. Montane species range from lower tree line to mid elevations and tolerate warmer and drier conditions. Mesic species are associated with the warmer, wetter maritime conditions found west of the continental divide. The biome types used in Rehfeldt et al. come from Brown (1994) and Brown et al. (1998). Their classification scheme is based on the distributions of flora and fauna without reliance on physiography and altitudinal zonation of vegetation is an integral part of the system.

\subsection{Data sets}

We obtained from the authors the projected vegetation data sets for the reference period and up to three future time periods to 2100 . The results of the Coops and Waring study were downloaded from Data Basin (databasin.org on January 7, 2014). Those of Crookston et al. were downloaded from http://forest.moscowfsl.wsu.edu/climate/species/index.php on October 9, 2014 and Rehfeldt et al. from http://forest.moscowfsl.wsu.edu/climate/ publications.php on October 22, 2013. The other data sets were provided by the authors.

All data sets were converted from various file types to raster grids, projected into the same coordinate system and each were clipped to the GNLCC study area boundary. Because data sets varied in spatial resolution $(800-5000 \mathrm{~m})$, relative area of suitable climate (percent of study area) was used rather than absolute area to avoid having to change cell sizes thus creating unnecessary resampling and scaling.

Locations of predicted presence were additionally described by land allocation. Land allocation was derived from Theobald (2014), USDA Forest Service (2003) and USGS (1997). Classes derived from these data sets were: private; private protected and nonfederal public; federal general use; federal restricted use; and other. These classes are relevant to the potential for conservation and adaptation strategies to cope with climate change. They differ in the priority level of conservation objectives, the legal mandates for active management, and the logistic difficulty of coordinated management across the larger spatial scales relevant to management under climate change.

\subsection{Analysis of climate suitability}

We first made raster maps of the species suitability data we compiled from each study for each species and time period. We then calculated the percent of the spatial unit of interest that was projected to have suitable climate for each time period and each species. Spatial units were the full extent of the study area, the Greater Yellowstone PACE, and the Glacier PACE. The reference periods varied among studies from 1961-1990 to 1981-2010 (Table 1). Future periods also differed among studies but were in the following ranges: 2020-2040, 2050-2069, 2070-2100. In order to illustrate the trajectory of change climate suitability, we mapped for each species the locations of suitable climates for each species and time period, distinguishing locations where climate suitability during the reference period was retained vs lost in the future projections. We then summarized the aerial extent of suitable climate during the reference period, loss of reference -period suitable climate in future periods, and gain in suitable climate in future periods. For newly suitable habitats, we distinguished between those near enough to currently suitable habits to have some probability of colonization from those more distant from potential source areas (see below). These summaries were done separately for each tree species or biome type, geographic unit, climate scenario, and study.

\subsection{Vulnerability assessment}

We assessed components of vulnerability based exclusively on climate suitability (Table 3 ). Vulnerability has been defined as a function of: exposure - the magnitude of change experienced; sensitivity - the degree to which that change impacts the system; and adaptive capacity - the ability to respond or cope with the change (IPCC, 2007). Climate niche model approaches consider exposure (climate change) and sensitivity (species tolerances to climate in the presence of other species and project the potential impact of climate change on the locations of suitable climate for a species. Thus, we evaluate vulnerability based on potential impact, which is an objective output of the statistical models. However, we do not consider adaptive capacity, which is usually derived from expert opinion.

From each of the studies we drew on estimated area of suitable climate during a reference period thought to be representative of the tolerances of tree species prior to the increased rate of climate warming in the mid 1980s. Each of the study authors obtained locations where tree species were present from FIA data, selected climate data for the reference period from meteorological 
Table 3

Criteria used to assess vulnerability of tree species.

\begin{tabular}{|c|c|c|c|}
\hline Time period & Metric & Units & Vulnerability ranking scheme \\
\hline Current period & Area of suitable habitat & Percent of study area & $\begin{array}{l}\text { 5: Very high }(<10 \% \text { of area }) \\
\text { 4: High }(10<30 \% \text { of area }) \\
\text { 3: Medium }(30<50 \% \text { of area }) \\
\text { 2: Low }(50<75 \% \text { of area }) \\
\text { 1: Very low }(>=75 \% \text { of area })\end{array}$ \\
\hline \multirow[t]{3}{*}{$\begin{array}{l}\text { Late century } \\
\quad(\text { e.g., 2070-2090) }\end{array}$} & $\begin{array}{l}\text { Loss of reference-period } \\
\text { suitable habitat }\end{array}$ & $\begin{array}{l}\text { Percent loss of area from } \\
\text { the reference period }\end{array}$ & $\begin{array}{l}\text { 5: Very high }(>75 \%) \\
\text { 4: High }(>50-75 \%) \\
\text { 3: Medium }(>30-50 \%) \\
\text { 2: Low }(>10-30 \%) \\
\text { 1: Very low }(<=10 \%)\end{array}$ \\
\hline & $\begin{array}{l}\text { Naturally colonizable newly } \\
\text { suitable habitat by } 2070-2090\end{array}$ & $\begin{array}{l}\% \text { Gain in suitable habitat that } \\
\text { is potentially colonizable } \\
\text { (<=30 km from reference suitable habitat) }\end{array}$ & $\begin{array}{l}0 \text { : very low gain }(0<10 \%) \\
-1 \text { : low gain }(10<50 \%) \\
-2: \text { mod gain }(50<100 \%) \\
-3 \text { : large gain }(100<150 \%) \\
-4: \text { very large gain }(>=150 \%)\end{array}$ \\
\hline & $\begin{array}{l}\text { Newly suitable habitat by } \\
2070-2090 \text { requiring assisted migration }\end{array}$ & $\begin{array}{l}\text { Percent gain in suitable habitat that } \\
\text { is not colonizable ( }>30 \mathrm{~km} \text { from reference } \\
\text { suitable habitat) }\end{array}$ & $\begin{array}{l}0 \text { : low gain }(0<20 \%) \\
-1: \text { mod gain }(20<100 \%) \\
-2: \text { large gain }(>100 \%)\end{array}$ \\
\hline
\end{tabular}

station-derived sources (e.g., PRISM), developed statistical functions relating tree presence to climate, and used these functions to map areas of suitable climate for the reference period. We used the aerial extent of this modeled suitable climate during the reference period as a measure of vulnerability to extinction within the study area. This is consistent with studies showing occupied area is a strong predictor of local extinction (Pearson et al., 2014) and the vegetation studies demonstrated that actual presence was strongly related to modeled suitability.

Locations that were projected in the studies to have suitable climate for a tree species under future climate scenarios were divided into three classes for the vulnerability analysis. Locations suitable in climate in the reference period and in the 2070-2090 period were distinguished because tree species are likely to be present in these locations now and given the longevity of these tree species, likely to continue to support tree populations into the future. Locations that are projected to become suitable by 2070-2090 and are within $30 \mathrm{~km}$ of currently suitable locations are distinguished because there is a reasonable probability that they will be colonized by the tree species and contribute to the persistence of the population. Newly suitable locations beyond the $30 \mathrm{~km}$ threshold are distinguished because they are candidate sites for assisted migration of these tree species.

We selected $30 \mathrm{~km}$ as the threshold based on conclusions from published studies. Maximum rates of tree population expansion during the Holocene were $50 \mathrm{~km}$ per century (Davis and Shaw, 2001). Current levels of fragmentation resulted in species with this potential rate expanding at $1-10 \mathrm{~km}$ per century in a simulation study (Schwartz, 1993). Iverson et al. (2004) found that none of the five tree species simulated had more than a $1 \%$ average probability of colonization beyond $30 \mathrm{~km}$ over 100 years along a north south transect in the mid-Atlantic states.

Consistent with Thomas et al. (2011) and Foden et al. (2013), we elected to assign cardinal variable rankings for each vulnerability metric as a basis for comparisons among species and as a way to derive an overall index of vulnerability for a species from the sum of the predictors (Table 3 ). The values for each of these vulnerability elements were combined into an overall vulnerability score. Summary scores for each tree species were then ranked to establish their relative vulnerability. This resulted in summary scores for the GNLCC that ranged from a minimum of -1.5 (low impact) to a high of 6.5 (high impact); scores between 1.5 and 4.5 are considered 'moderate' impact.

This vulnerability ranking was done with results for each study, geographic area (GNLCC and Greater Yellowstone and Glacier
PACEs), and climate scenario (A2, B1). We report in the results the degree of consensus in the species rankings among scenarios, geographic areas and studies and point out instances of disagreement.

\section{Results}

\subsection{Climate suitability of biome types}

Climate suitability for biome types shifted substantially between the reference and the projections for the end of the century under the consensus scenarios and GCMs used by Rehfeldt et al. (Fig. 2). Across the GNLCC, the Western alpine tundra, Rocky Mountain subalpine conifer, Rocky Mountain montane conifer, and Great Basin shrub-grassland types that dominate during the reference period declined in suitable area throughout the century. The subalpine and montane conifer types were projected to be largely replaced in climate suitability by the nonforest types of Great Basin montane scrub, Great Basin desert scrub, Plains grassland, and Great Basin conifer woodland. The projected biome shifts in Greater Yellowstone were more extreme that for GNLCC with conifer forest types dropping from $82 \%$ of the area to $26 \%$ and scrub types increasing from $0 \%$ to $48 \%$ of the area. The Glacier PACE was projected to shift in climate suitability from subalpine conifer to Interior cedar-hemlock conifer, Northeast deciduous (which includes aspen), and Great Basin montane scrub.

\subsection{Climate suitability of tree species}

Across the GNLCC, the four studies all projected substantial declines in area of suitable climate for the four subalpine tree species over the coming century (Fig. 3, Appendix 1). The projected loss was greatest for Whitebark pine. The proportion of the LCC with suitable climate for this species dropped from just over $20 \%$ in the reference period to $0.5-7.0 \%$ by $2070-2100$ under the A2 scenario. Area with suitable climate for Englemann spruce, Subalpine fir, and Lodgepole pine dropped from $30 \%$ to $45 \%$ of the LCC during the reference period to $<10 \%$ by late century under the A2 scenario, except Coops \& Waring projected 30\% remaining suitable for Subalpine fir. Trends were similar under the B1 scenario (Appendix 1) and under the consensus scenario of Gray \& Hamann, but somewhat less extreme in loss of area of suitable climate.

Among Montane species under the A2 scenario, the studies agreed in projecting increased climate suitability for Ponderosa 


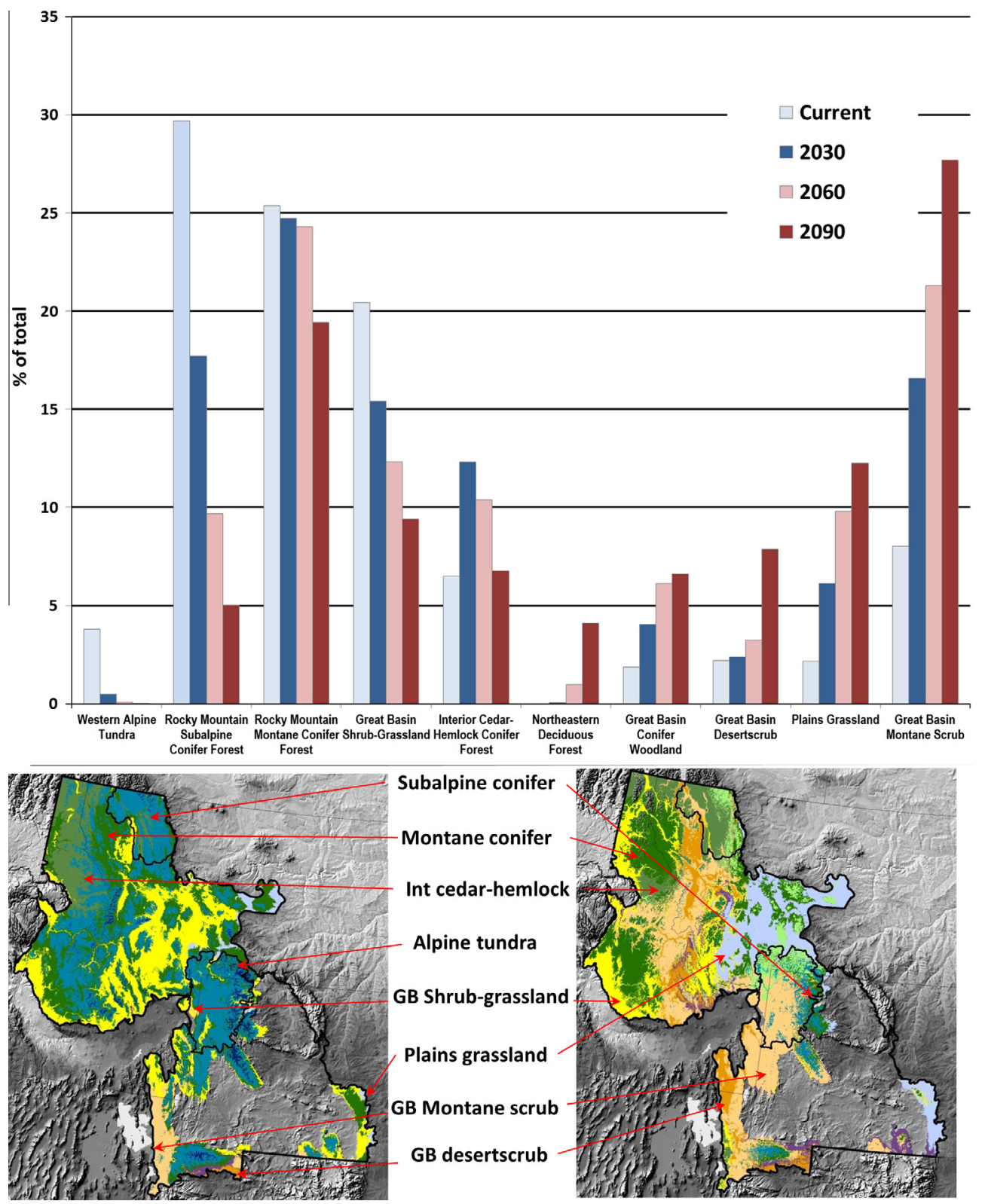

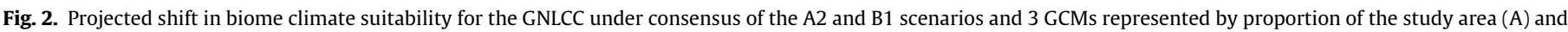
location (B).

pine and Grand fir. Coops \& Waring projected substantial increases for Douglas fir and Western larch. In contrast, Crookston et al. projected substantial decreases for these species. Gray \& Hamann also showed decreases in climate suitability for Western larch and little change in Douglas fir. These trends were similar in slope but slightly less pronounced under the B1 scenario.

Among the mesic tree species under the A2 scenario, Mountain hemlock was projected to decrease from about $7 \%$ of the LCC in the reference period to about $5 \%$ in $2070-2100$ by Coops \& Waring, to remain below $2 \%$ by Crookston et al. and Hamann \& Gray. Western hemlock was projected to have little suitable climate area by Crookston et al. and Gray \& Hamann, but Coops \& Waring projected substantial increases. The studies also disagree on Western redcedar with Gray \& Hamann projecting little suitable area, Crookston et al. projecting slight increases, and Coops \& Waring projecting substantial increases. Again, trends under the B1 scenario were similar to A2 but less extreme.
The results for Greater Yellowstone differed from those for the GNLCC is a few important ways (Appendix 2). Climate suitability for the subalpine species covered a much larger proportion of the PACE in the current period and the percentage decline in suitable area by 2100 is larger than for the GNLCC. Coops \& Waring projected a small increase in climate suitability for subalpine fir, unlike the drop that the other studies projected for the Greater Yellowstone and that Coops \& Waring and the other studies projected across the LCC. Coops \& Waring also projected large increases in Douglas fir, Western Larch, Grand fir, Western redcedar, and Mountain hemlock in Greater Yellowstone. In contrast, Crookston et al. and Gray \& Hamann projected a decrease in Douglas fir and little suitable habitat for Western larch, Grand fir, Western redcedar, and Western hemlock in Greater Yellowstone.

In the Glacier, climate suitability for subalpine species was also projected to decline substantially (Appendix 3). Unlike Greater Yellowstone, however, Montane species were projected to continue to 
Subalpine
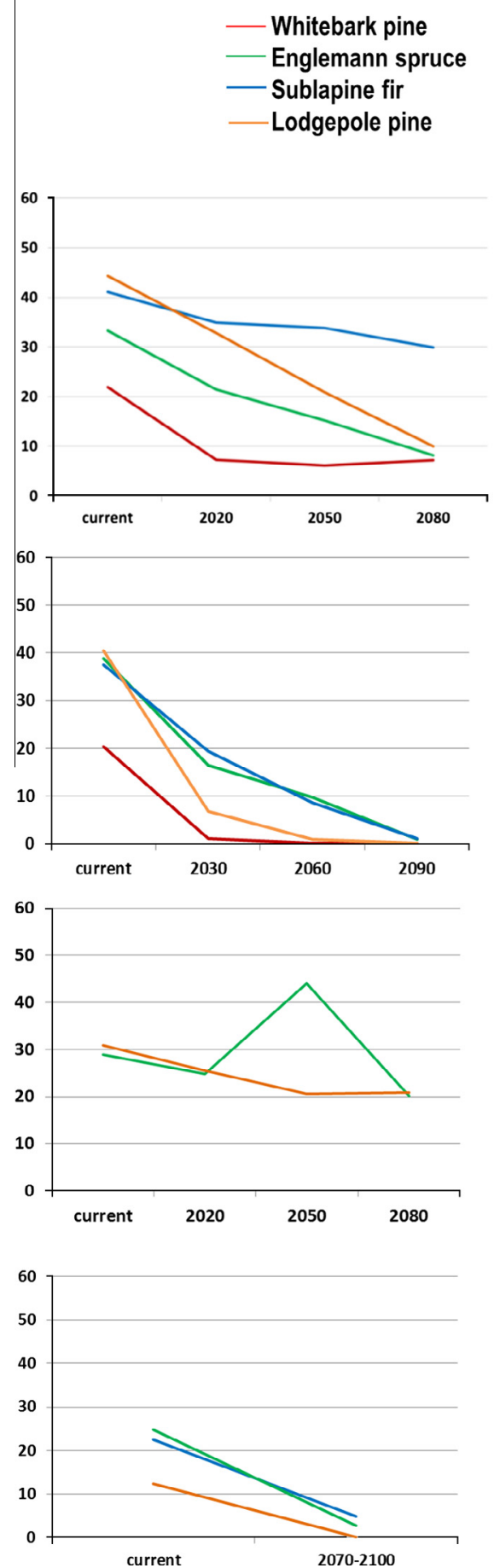

Montane
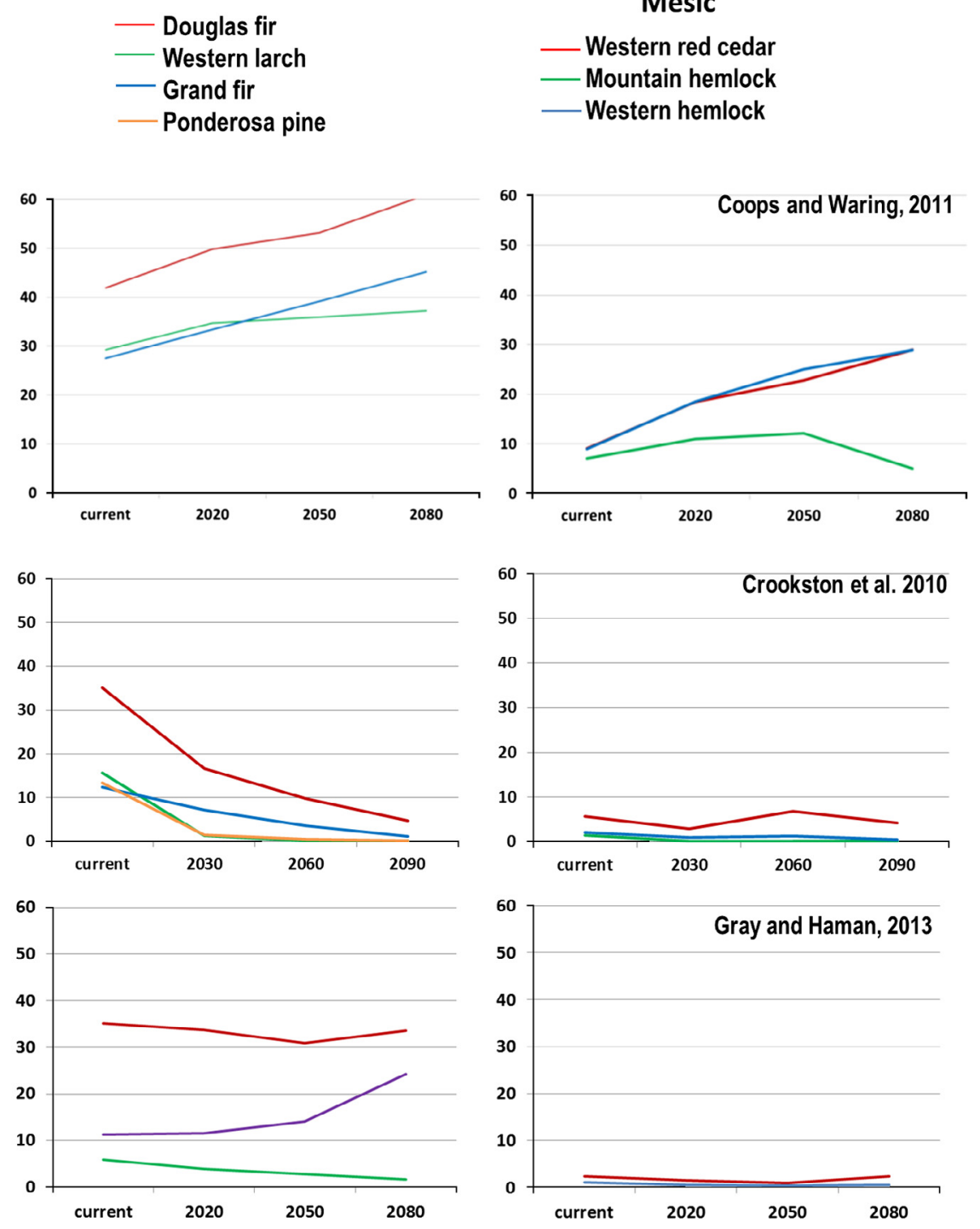

Bell et al. 2014

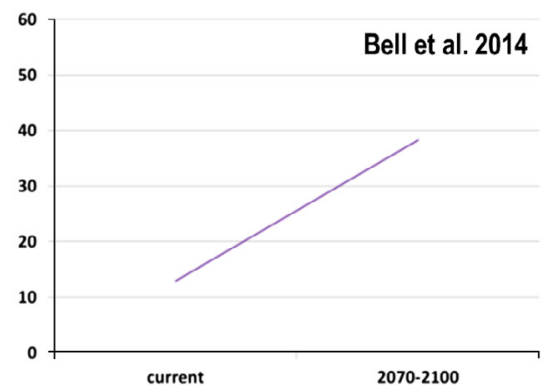

- Western red cedar

- Mountain hemlock

—Western hemlock

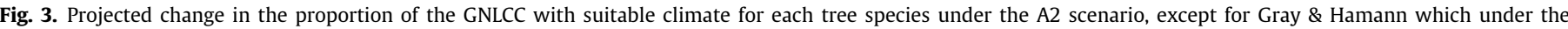
consensus of 4 scenarios.

have high climate suitability throughout the century. Climate suitability for mesic species was projected to expand, albeit slowly for Mountain hemlock.

The spatial patterns of change in climate suitability across the GNLCC varied among the subalpine, montane, and mesic guilds of tree species. For the subalpine species, climate suitability contracted substantially from the reference period to future periods and newly suitable areas were at higher elevations (Fig. 4). This resulted in major reductions in total area of suitable climate because of the lack of land area on mountain tops. However, nearly all of the newly suitable locations were relatively close to currently suitable areas suggesting that expansion of these populations may be able to track climate change. Montane species generally expanded from mid elevations to adjacent higher elevations that are currently occupied by subalpine species (Fig. 5). Again, the newly suitable locations were generally within the threshold distance for possible population expansion. Climate suitability for Grand fir, Western larch, and Ponderosa pine, however, expanded in some locations east of the continental divide, where they had little suitable habitat in the reference period. Suitable climates 


\section{Whitebark pine}
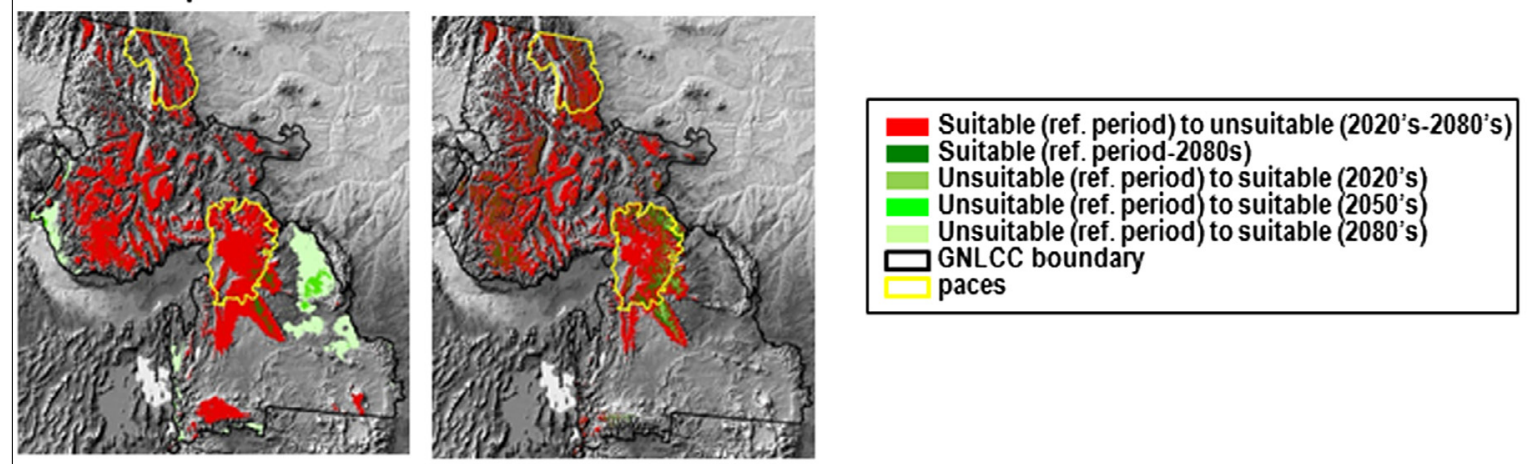

\section{Englemann Spruce}
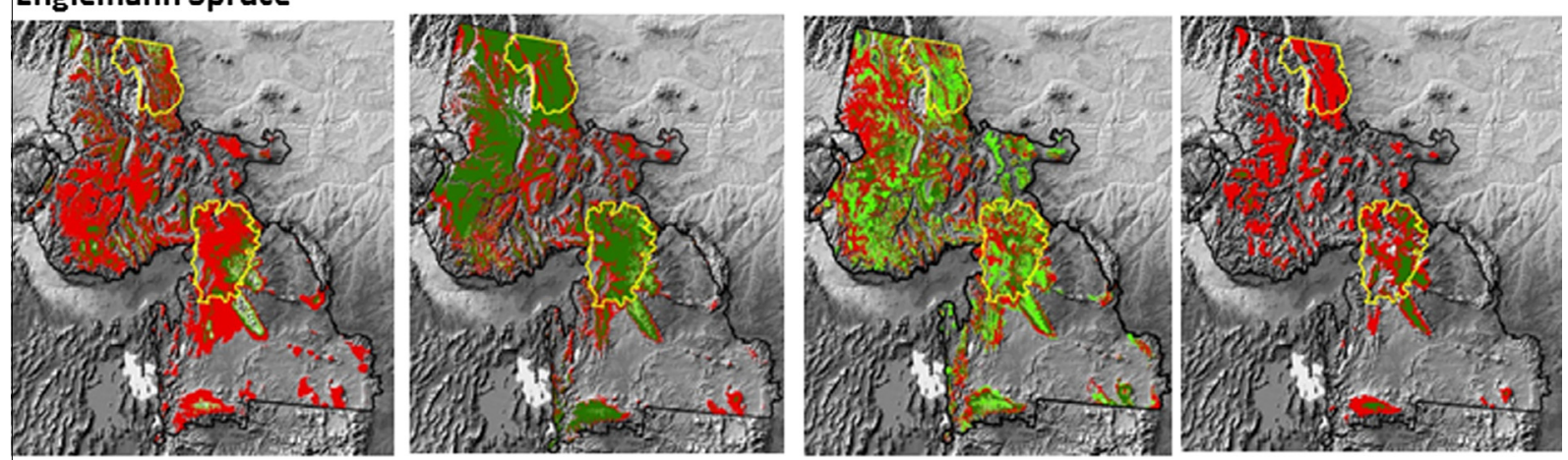

Subalpine fir
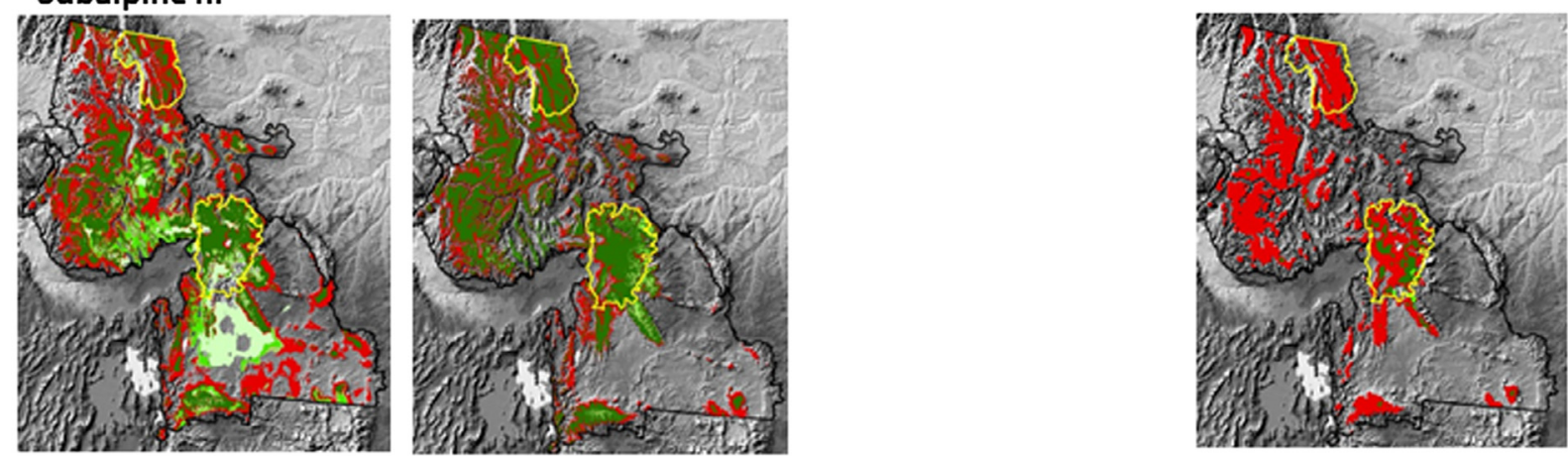

Lodgepole pine

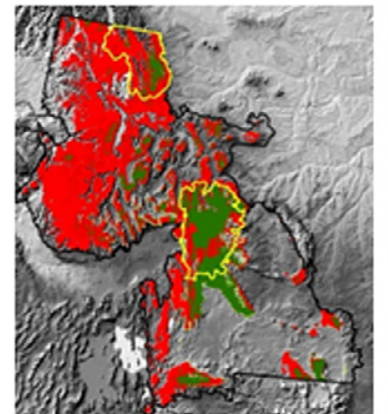

Coops \& Waring 2011

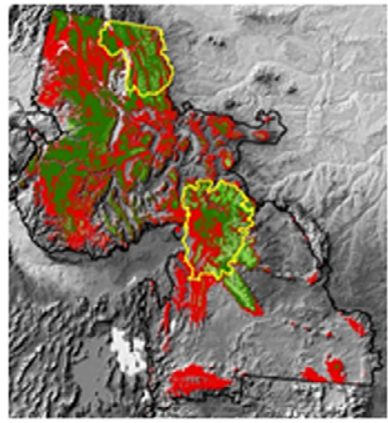

Crookston et al. 2010

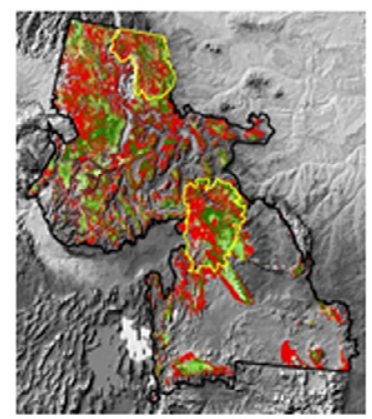

Gray \& Hamann 2013

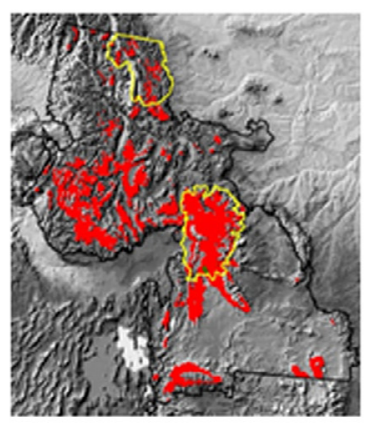

Bell et al. 2014

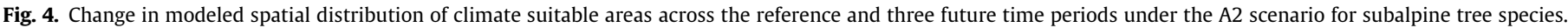

for the mesic species were projected to expand by Coops \& Waring from their current west-side locations to hundreds of km eastward (Fig. 6), however Crookston et al. and Gray \& Hamann projected no such shifts to eastside locations. Importantly, both Coops \& Waring and Crookston et al. both project substantial contraction of suitable climate area for Mountain hemlock in the western portion of the study area where the species is currently present.
The distributions of suitable climates for tree species among land allocation types shifted from the reference period to the late-century period. The major trend toward reductions in suitable climate on private and federal lands and increases in suitable climate on federal restricted lands (Fig. 7). Consistent with the trend of climate suitable for a species shifting upward in elevation, climate suitability for most species shifted from federal unrestricted 
Douglas fir
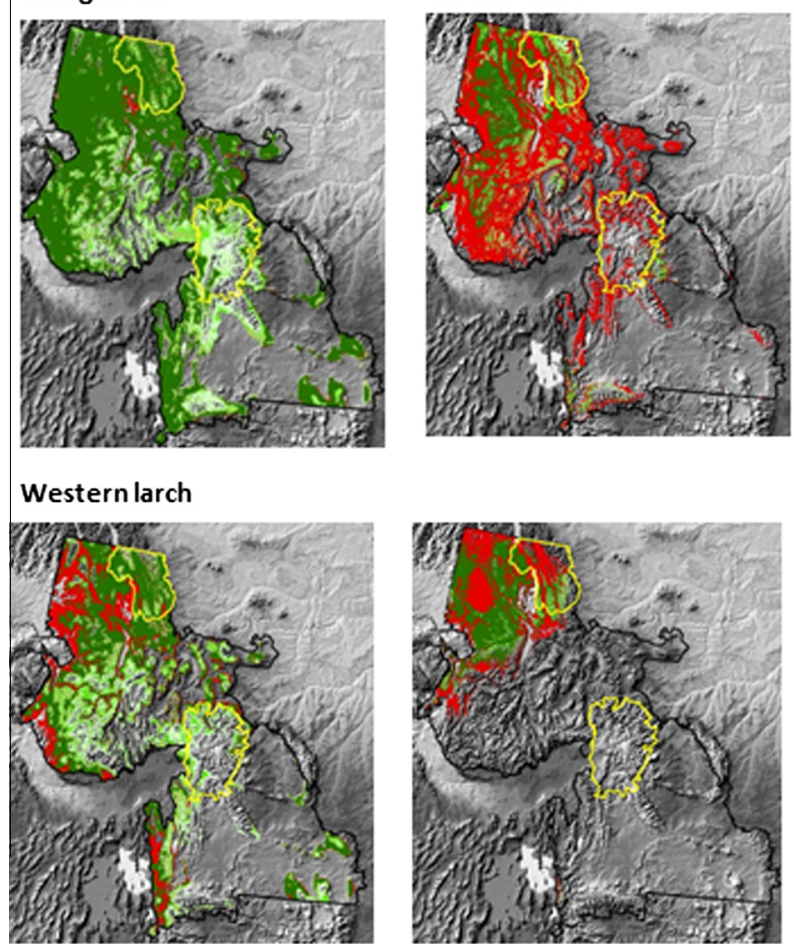

Ponderosa pine
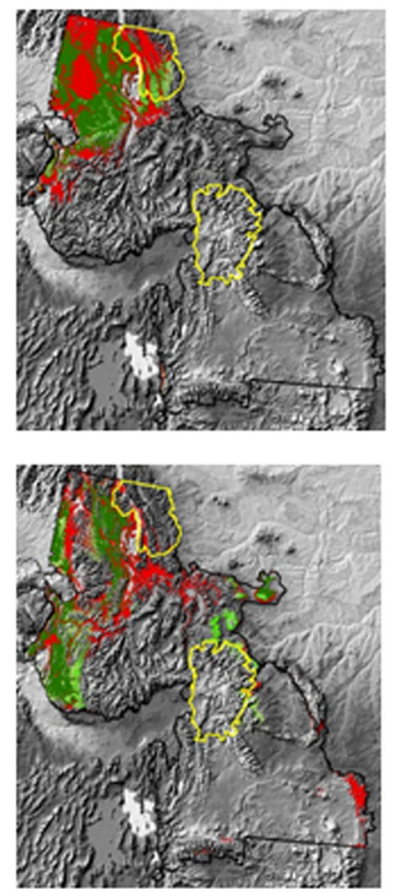

Crookston et al. 2010
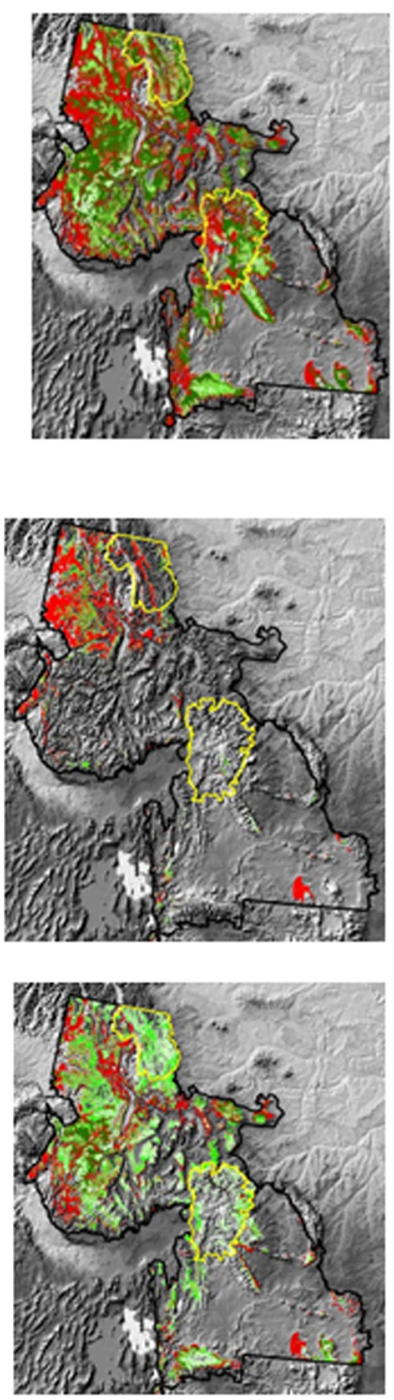

Gray \& Hamann 2013

Coops \& Waring 2011

Bell et al. 2014

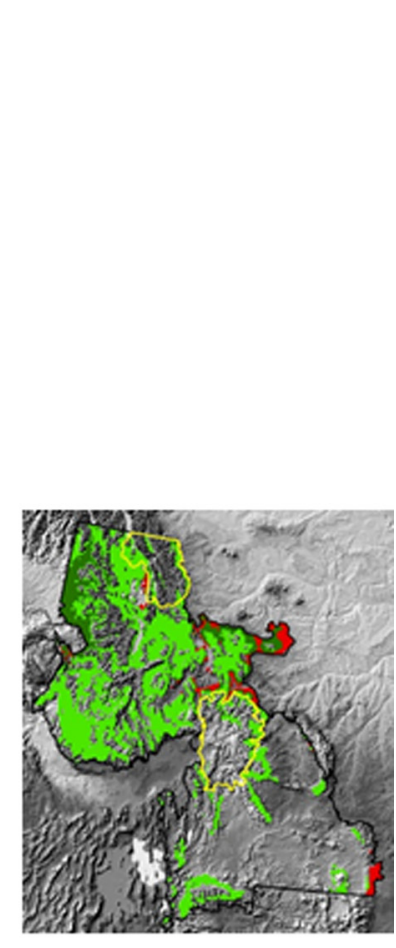

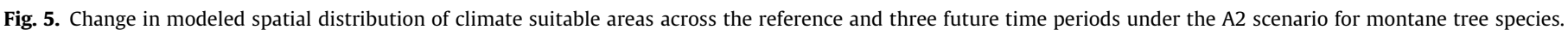

lands such as USFS general forest to the National Parks, Wilderness Areas and Roadless areas that are generally at higher elevations.

\subsection{Vulnerability scores}

Only a very small proportion of the study area was classified as suitable for the three mesic species (Table 4). This was expected because their primary distributions are in the warmer, moister settings closer to the Pacific Ocean. Projected declines in suitable habitat for these species by 2090 under the A2 scenario were relatively high (45-60\% of currently suitable habitat when averaged among studies). These losses were more than offset by projected gains, however, for Western Hemlock and Western redcedar. This was not the case for Mountain hemlock, which had relatively little area of projected newly suitable habitat.

Among the montane and subalpine species, Whitebark pine had the smallest proportion of current suitable habitat at about $20 \%$ of the study area. Douglas fir, Lodgepole pine, Englemann spruce had relatively large proportions of current suitable habitat. Whitebark pine had a substantially higher projected rate of decline $(74 \%$ of current when averaged among studies) than other subalpine and alpine species. Projected gains in suitable habitat with $30 \mathrm{~km}$ of currently suitable habitat more than offset projected declines for all of these species except Whitebark pine. Projected gains in suitable habitat at distances beyond the $30 \mathrm{~km}$ threshold were small for all species except Ponderosa pine, Western redcedar, and Western hemlock. 
Mountain hemlock

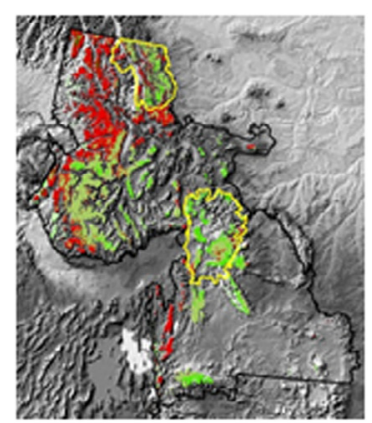

\section{Western hemlock}

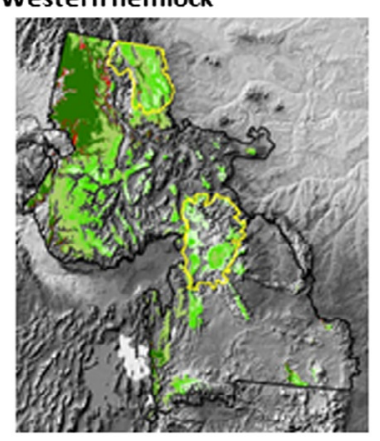

Western redcedar

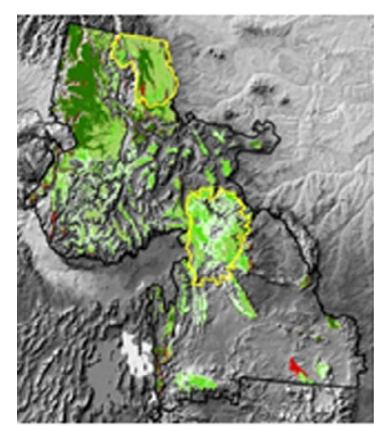

Coops \& Waring 2011

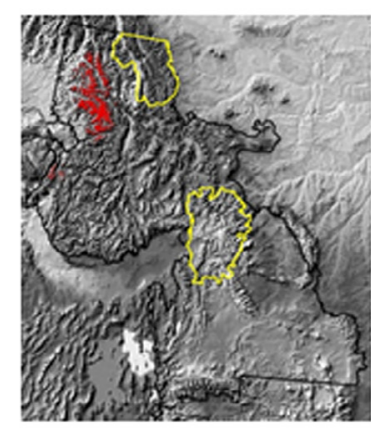

\begin{tabular}{|l|}
\hline Suitable (ref. period) to unsuitable (2020's-2080's) \\
Suitable (ref. period-2080s) \\
Unsuitable (ref. period) to suitable (2020's) \\
Unsuitable (ref. period to suitable (2050's) \\
Unsuitable (ref. period) to suitable (2080's) \\
$\square$ GNLCC boundary \\
paces
\end{tabular}
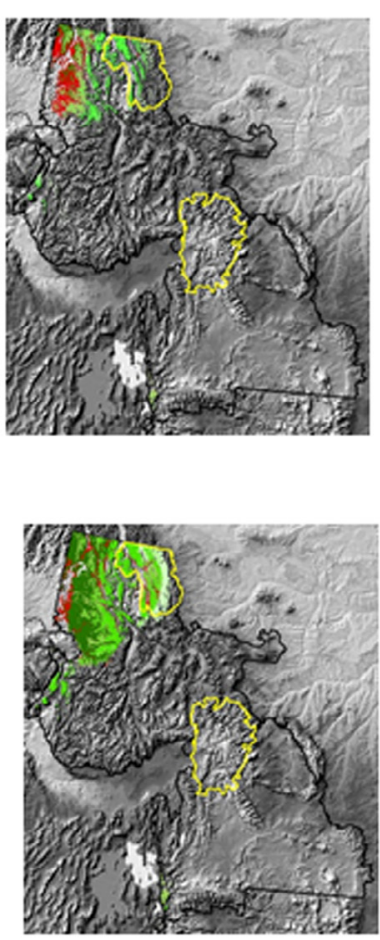

Crookston et al. 2010
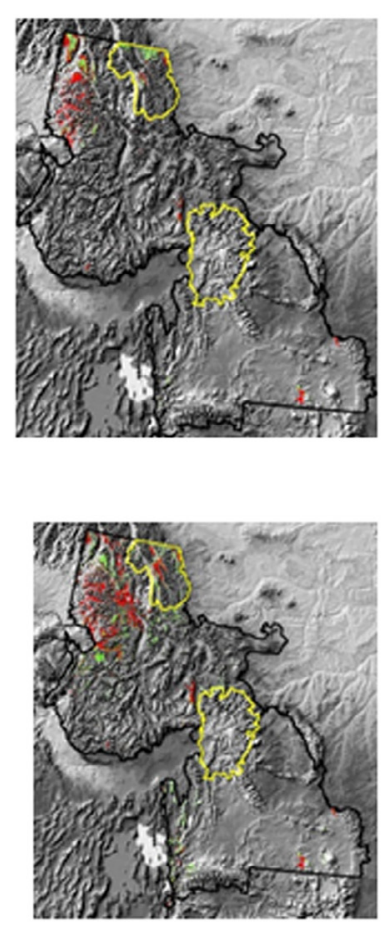

Gray \& Hamann 2013
Bell et al. 2014

Fig. 6. Change in modeled spatial distribution of climate suitable areas across the reference and three future time periods under the A2 scenario for mesic tree species.

The cardinal ranking of these results under the vulnerability criteria in Table 3 indicated that Whitebark pine and Mountain hemlock were most vulnerable by a wide margin (Table 5, Fig. 8). Being restricted to the coldest portions of the subalpine, Whitebark pine has relatively little area of suitable habitat currently and was projected to undergo substantial declines in suitable habitat with little new habitat becoming suitable. Mountain hemlock scored high in vulnerability score, largely due to a very small area of currently suitable habitat and substantial projected losses of suitable habitat. Subalpine fir and Lodgepole pine were also placed in the high vulnerability class because of the large decline in projected suitable area and low gain in newly suitable areas. Western hemlock, Western redcedar, Western larch, Douglas fir and Ponderosa pine were considered Medium in vulnerability. Grand fir was projected to gain substantially in area of suitable habitat and was considered Low in vulnerability.

Level of agreement among the studies (based on relatively low standard deviations among studies) was relatively high for most species, but lower for Mountain hemlock, Western hemlock, and Ponderosa pine (Fig. 8).
Among the species currently present in the Greater Yellowstone PACE and in the Glacier PACE, order of vulnerability ranking under the A2 climate scenario was similar to that of the GNLCC, with Whitebark pine having the highest vulnerability score (Appendix 4). The score for Mountain hemlock in Glacier was nearly as high as Whitebark pine, just as was the case for the GNLCC. The order of vulnerability rankings under the B1 climate scenario was similar to those under A2, but the values were lower than under A2 due to the less extreme climate projections (Appendix 5). The vulnerability scores and ranks among species under the B1 climate scenario were very similar to those under A2 (Appendix 5).

\section{Discussion}

Many papers have been published in recent years on climate suitability for species under scenarios of future climate change. Most of these efforts are at sub-continental to continental scales and have addressed fundamental questions about the potential species responses to climate change. These studies represent a valuable resource for informing conservation and management 
Subalpine
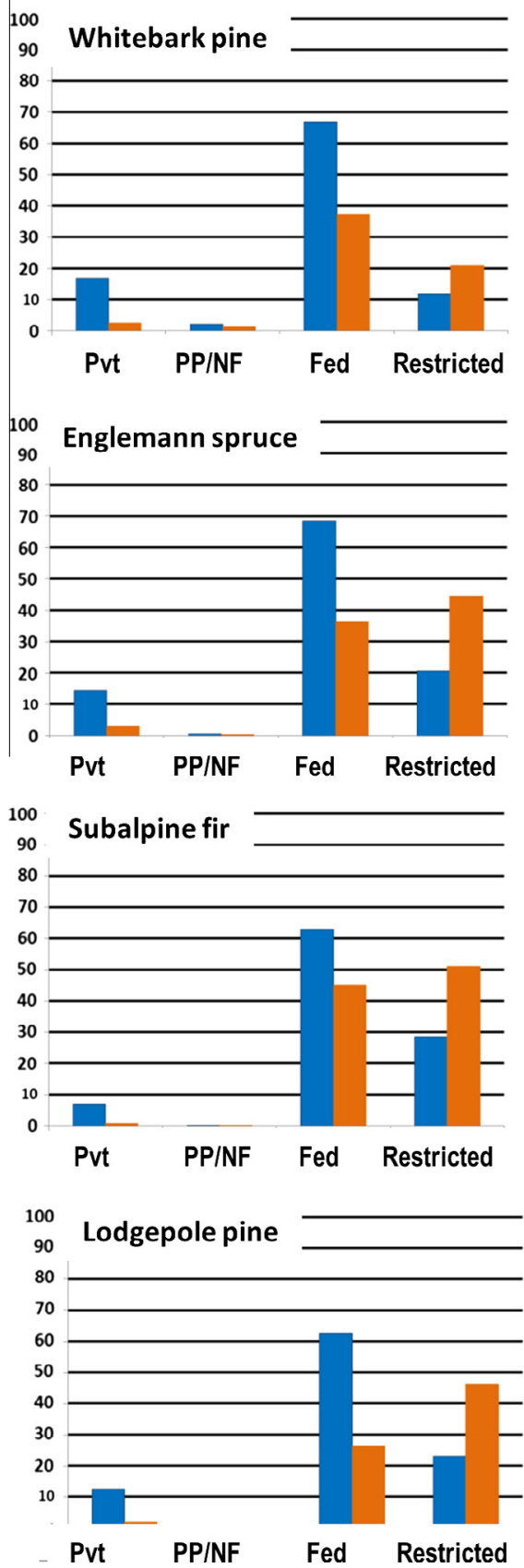
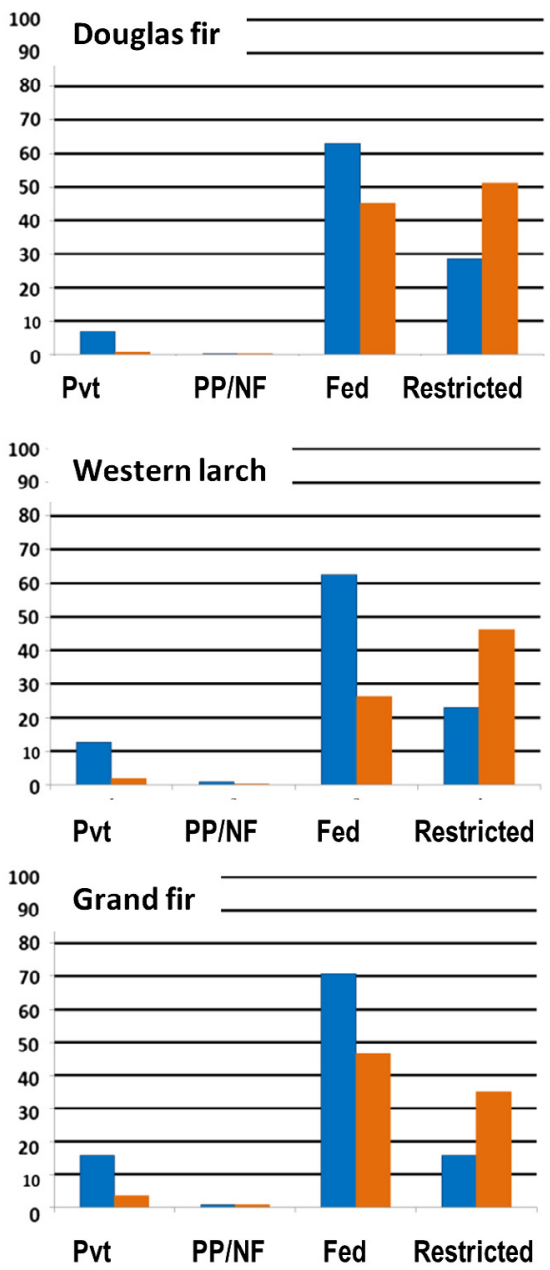

Mesic
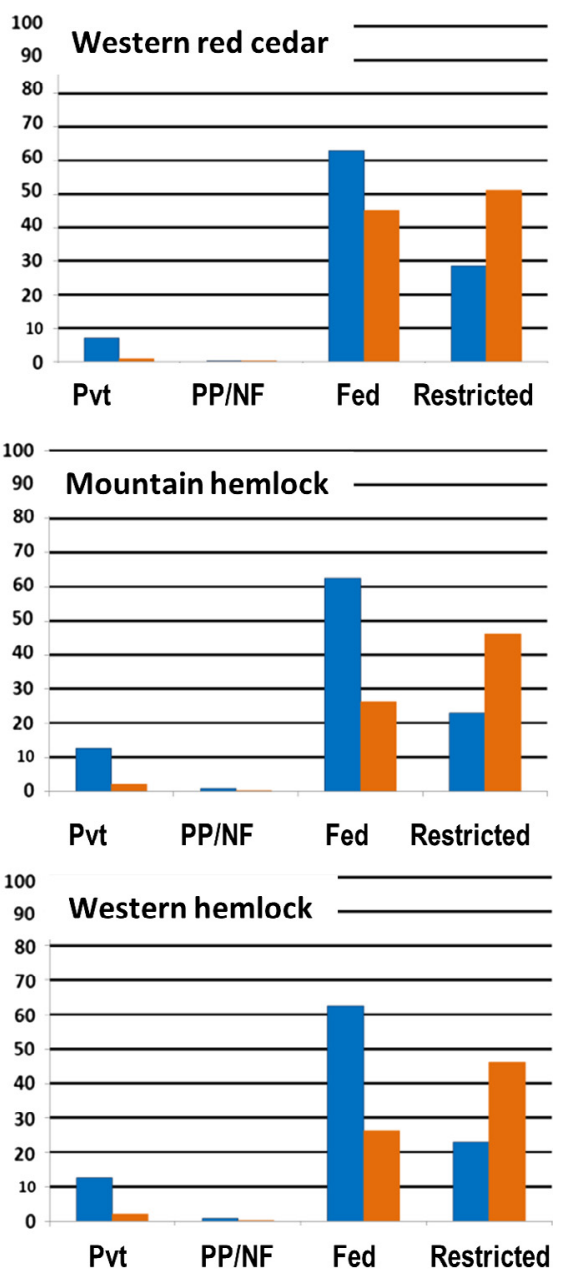

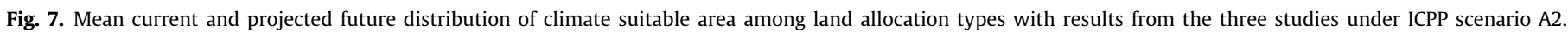
Abbreviations for land allocation types are: PVT - private; PP/NF - private protected and nonfederal public; Fed - federal multiple use; Restricted - federal restricted.

within the local to regional scales within which climate adaptation planning is being done. In this study we synthesized the results of five studies of tree species or biome type climate suitability under climate change for geographic areas of high interest for management: the GNLCC and two national park-centered ecosystems within it, the Greater Yellowstone and Glacier PACEs. We reported current and projected future climate suitability for each of 11 species and for biome types for each of the studies under two climate scenarios, assessed vulnerability based on the results of each study, and then examined the level of agreement in both climate suitability projections and vulnerability rankings among the studies. Level of agreement in vulnerability rankings among studies that differ in climate predictors, GCMs, and statistical models is a measure of uncertainty in vulnerability, which is of high interest to resource managers. Moreover, the results of climate suitability modeling are highly relevant for designing adaptation strategies for vulnerable species.

The four studies of tree species climate suitability were in agreement on the ranking of the species receiving the highest vulnerability scores. These species were those in the subalpine guild and Mountain hemlock in the mesic guild. Among these, Mountain hemlock and Whitebark pine had the smallest area of suitable climate in the current period, the largest loss of this suitable habitat by 2100 , and the least area of newly suitable habitat. Results for the other subalpine species, Englemann spruce, Subalpine fir, and Lodgepole pine, were similar but less extreme. Agreement among the three studies on the vulnerability of these species lends credibility that these species most merit the attention of resource 
Table 4

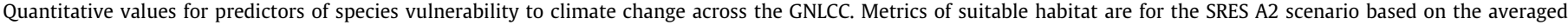
projections among the studies considered.

\begin{tabular}{|c|c|c|c|c|c|c|c|c|c|c|c|c|}
\hline \multirow{2}{*}{ Predictors } & \multirow[t]{2}{*}{ Study } & \multicolumn{11}{|c|}{ Species } \\
\hline & & PIAL & PIEN & ABLA & PICO & PSME & LAOC & ABGR & PIPO & TSME & TSHE & THPL \\
\hline \multirow[t]{4}{*}{ Reference suitable area } & Coops \& Waring & 0.22 & 0.33 & 0.40 & 0.43 & 0.41 & 0.29 & 0.27 & & 0.07 & 0.09 & 0.09 \\
\hline & Crookston et al. & 0.20 & 0.39 & 0.38 & 0.40 & 0.35 & 0.16 & 0.12 & 0.13 & 0.01 & 0.02 & 0.06 \\
\hline & Gray \& Hamann & & 0.29 & & 0.31 & 0.35 & 0.06 & & 0.11 & & 0.01 & 0.02 \\
\hline & Bell et al. & & 0.18 & 0.22 & 0.17 & & & & 0.07 & & & \\
\hline \multirow{4}{*}{$\begin{array}{l}\text { Projected decline in reference } \\
\text { suitable habitat }\end{array}$} & Coops \& Waring & 0.66 & 0.41 & 0.22 & 0.30 & 0.01 & 0.11 & 0.08 & & 0.62 & 0.06 & 0.60 \\
\hline & Crookston et al. & 0.81 & 0.35 & 0.35 & 0.54 & 0.36 & 0.49 & 0.10 & 0.51 & 0.99 & 0.71 & 0.16 \\
\hline & Gray \& Hamann & & 0.12 & & 0.31 & 0.19 & 0.61 & & 0.39 & & 0.82 & 0.64 \\
\hline & Bell et al. & & 0.84 & 0.92 & 1.00 & & & & 0.30 & & & \\
\hline \multirow{4}{*}{$\begin{array}{l}\% \text { Gain in suitable habitat }<=30 \mathrm{~km} \\
\text { to reference suitable habitat }\end{array}$} & Coops \& Waring & 0.41 & 0.66 & 1.08 & 0.74 & 1.45 & 1.48 & 1.61 & & 1.91 & 2.18 & 2.72 \\
\hline & Crookston et al. & 0.22 & 0.68 & 0.68 & 0.54 & 0.81 & 0.60 & 1.49 & 0.72 & 0.00 & 1.64 & 1.98 \\
\hline & Gray \& Hamann & & 1.54 & & 0 & 1.23 & 0.98 & & 2.51 & & 1.01 & 1.37 \\
\hline & Bell et al. & & 0.16 & 0.09 & 0 & & & & 2.07 & & & \\
\hline \multirow{4}{*}{$\begin{array}{l}\% \text { Gain suitable habitat }>30 \mathrm{~km} \\
\text { to reference suitable habitat }\end{array}$} & Coops \& Waring & 0.21 & 0 & 0.03 & 0 & 0.02 & 0.02 & 0.22 & & 0.21 & 1.09 & 0.60 \\
\hline & Crookston et al. & 0 & 0 & 0 & 0 & 0 & 0.16 & 0.01 & 0.02 & 0.00 & 0.40 & 0.09 \\
\hline & Gray \& Hamann & & 0 & & 0 & 0 & 0.01 & & 0.10 & & 0.02 & 0.19 \\
\hline & Bell et al. & & 0 & 0 & 0 & & & & 2.26 & & & \\
\hline
\end{tabular}

Table 5

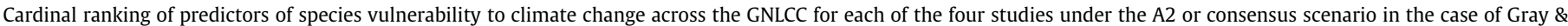
Hamann. Higher scores indicate greater vulnerability.

\begin{tabular}{|c|c|c|c|c|c|c|c|c|c|c|c|c|}
\hline \multirow[t]{2}{*}{ Predictors } & \multirow[t]{2}{*}{ Study } & \multicolumn{11}{|c|}{ Species } \\
\hline & & PIAL & PIEN & ABLA & PICO & PSME & LAOC & ABGR & PIPO & TSME & TSHE & THPL \\
\hline \multirow[t]{4}{*}{ Reference suitable area } & Coops \& Waring & 4 & 3 & 3 & 3 & 3 & 2 & 2 & & 5 & 5 & 5 \\
\hline & Crookston et al. & 4 & 3 & 3 & 3 & 3 & 4 & 4 & 4 & 5 & 5 & 5 \\
\hline & Bell et al. & & 3 & 3 & 3 & & & & 4 & & & \\
\hline & Gray \& Hamann & & 4 & & 3 & 3 & 5 & & 4 & & 5 & 5 \\
\hline \multirow{4}{*}{$\begin{array}{l}\text { Projected decline in reference } \\
\text { suitable habitat* }\end{array}$} & Coops \& Waring & 4 & 4 & 2 & 3 & 1 & 2 & 1 & & 4 & 1 & 4 \\
\hline & Crookston et al. & 5 & 3 & 3 & 4 & 3 & 3 & 1 & 4 & 5 & 4 & 2 \\
\hline & Bell et al. & & 5 & 5 & 5 & & & & 2 & & & \\
\hline & Gray \& Hamann & & 2 & & 3 & 2 & 4 & & 3 & & 5 & 4 \\
\hline \multirow{4}{*}{$\begin{array}{c}\% \text { Gain suitable habitat }<=30 \mathrm{~km} \\
\text { to reference suitable habitat }\end{array}$} & Coops \& Waring & -1 & -2 & -3 & -2 & -3 & -3 & -4 & & -4 & -4 & -4 \\
\hline & Crookston et al. & -1 & -2 & -2 & -2 & -2 & -2 & -3 & -2 & 0 & -4 & -4 \\
\hline & Bell et al. & & -1 & 0 & 0 & & & & -4 & & & \\
\hline & Gray \& Hamann & & -4 & & 0 & -3 & -2 & & -4 & & -3 & -3 \\
\hline \multirow{4}{*}{$\begin{array}{l}\% \text { Gain suitable habitat }>30 \mathrm{~km} \\
\text { to reference suitable habitat }\end{array}$} & Coops \& Waring & -1 & 0 & 0 & 0 & 0 & 0 & -1 & & -1 & -2 & -1 \\
\hline & Crookston et al. & 0 & 0 & 0 & 0 & 0 & 0 & 0 & 0 & 0 & -1 & 0 \\
\hline & Bell et al. & & 0 & 0 & 0 & & & & -4 & & & \\
\hline & Gray \& Hamann & & 0 & & 0 & 0 & 0 & & 0 & & 0 & 0 \\
\hline \multirow[t]{4}{*}{ Summary score } & Coops \& Waring & 6 & 5 & 2 & 4 & 1 & 1 & -2 & & 4 & 0 & 4 \\
\hline & Crookston et al. & 8 & 4 & 4 & 5 & 4 & 5 & 2 & 6 & 10 & 4 & 3 \\
\hline & Bell et al. & & 7 & 8 & 8 & & & & -2 & & & \\
\hline & Gray \& Hamann & & 2 & & 6 & 2 & 7 & & 3 & & 7 & 6 \\
\hline Average summary score & & 7.00 & 4.50 & 4.67 & 5.75 & 2.33 & 4.33 & 0.00 & 2.33 & 7.00 & 3.67 & 4.33 \\
\hline Std dev summary score & & 1.00 & 1.80 & 2.49 & 1.48 & 1.25 & 2.49 & 2.00 & 3.30 & 3.00 & 2.87 & 1.25 \\
\hline
\end{tabular}

managers. Similarly, agreement among the studies on the low vulnerability scores of Ponderosa pine and Grand fir lend credence that these species are not threatened by loss of climate suitability and that opportunities to facilitate expansion of these species to newly suitable climate locations will likely existing in the future. The disagreement of the studies on climate suitability and viability ranking of Douglas fir, Western hemlock, and Western redcedar may be primarily due to differences in GCMS used by Coops and Waring vs Crookston et al. and this is discussed further below.

In addition to vulnerability of tree species, the results raise question about the possibility of changes in vegetation lifeform in portions of the study area. If climate suitability for montane species does not develop in locations now suitable for subalpine species, vegetation life form would be expected to shift from coniferous forest to nonforest vegetation. Among the 74 tree species modeled by Crookston et al. across the western US, climate suitability was not projected to develop in these higher elevation eastside forests for any species not currently in the study area. Consistent with these projections for tree species climate suitability, the projections of biome suitability by Rehfeldt et al. suggested the replacement of conifer forests by desert shrub and grassland lifeform types. Such changes in lifeform, if realized, would have large implications for evapotranspiration, snow pack, runoff, and habitat for other species.

The only species projected to have suitable climate conditions in the higher elevations on the eastside of the study area was Douglas fir. Crookston et al. and Gray \& Hamann projected substantial declines in Douglas fir in current east side habitats but expansion of suitable habitat in the higher elevations of Greater Yellowstone. Coops \& Waring projected most of Greater Yellowstone being suitable for Douglas fir. They also projected Western hemlock, Western redcedar, Western larch and Mountain hemlock habitat expanding 


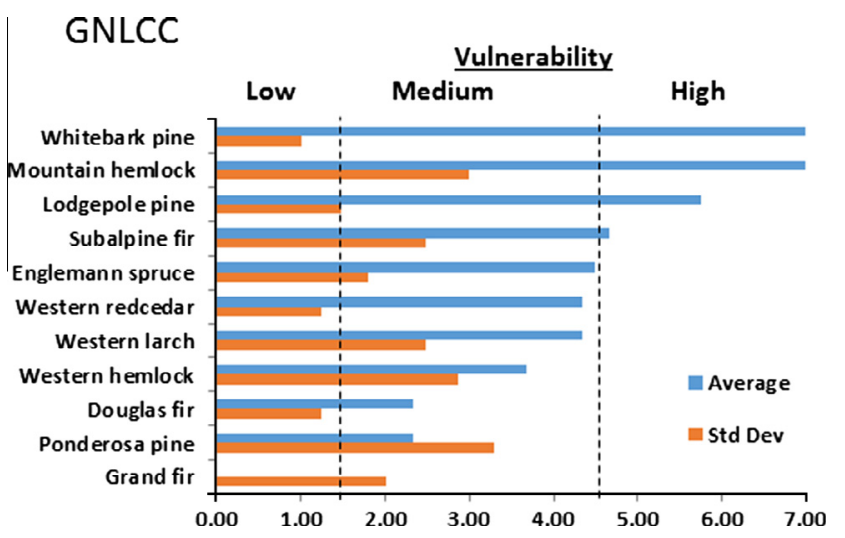

Fig. 8. Results of vulnerability assessment ranking averaged among studies under the A2 scenario.

into Greater Yellowstone. Thus, in contrast to the projections of Crookston et al. and Gray \& Hamann, those of Coops \& Waring suggested that these eastside subalpine areas would remain suitable for conifer trees, including Douglas fir and several other species now found on the west side of the study area.

The difference between Coops \& Waring and the other studies in climate suitability for montane and mesic tree species is likely due to the GCMs used for the climate projections. The single GCM used by Coops \& Waring (GCCM3) was found to project substantially cooler and wetter conditions in the Pacific Northwest than a 20 GCM ensemble average (Mote et al., 2005, 2008). The average among the three GCMs used by Crookston et al. (2010), the five GCMs used by Gray \& Hamann, and the 16 GCMS used by Bell et al. more closely resembled the 20 GCM ensemble average for the Pacific Northwest. Based on this, we suggest that substantial reductions in climate suitability for tree species in eastside subalpine habitats in the study area projected by the majority of studies is more credible that the expansion of climate suitability for these species projected by Coops \& Waring.

Other evidence tends to support reduced forest area and increased nonforest area in eastside subalpine habitats under future climates. Piekielek et al. (unpublished data) modeled habitat suitability for the major tree species and sagebrush across Greater Yellowstone under the IPCC CMIP 5 climate scenarios. In addition to climate, water balance, soils and topography were considered in the habitat models. Their results suggested a substantial reduction in subalpine tree species and Douglas fir under the CMIP5 RCP 8.5 scenario (equivalent to the SRES A1F1 scenario and warmer than the SRES A2 scenario, Mote et al., 2013) and an expansion sagebrush into higher elevations. Their results are consistent with the hypothesis that in addition to climate, lack of fertile soils may limit tree habitat suitability at higher elevations across Greater Yellowstone (Despain, 1990). Additional evidence comes from a study in the southwest US (Notaro et al., 2012) using a similar modeling approaches to those in this synthesis. They projected partial replacement of evergreen trees with grasses in the mountains of Colorado and Utah, except at the highest elevations, where tree cover increases. Also relevant are projections of a coarse-scale dynamic global vegetation model, which indicated a substantial reduction in the evergreen needle leaf plant functional type across the US Northern Rockies and increase in the shrub plant functional type (Jiang et al., 2013).

\subsection{Scope and limitations}

Several authors have emphasized (summarized by McKinney et al., 2011) that that the extent to which individual tree species will actually shift through natural processes interacting with climate change is highly uncertain, involving complex interacting factors such as: competitive, predatory, and mutualistic relationships among species, edaphic and land-use considerations, dispersal ability, genetic controls, $\mathrm{CO}_{2}$ fertilization effects, and disturbance patterns. Consequently, efforts to assess species vulnerability under climate change have used an expanding list of predictors beyond climate suitability for assessing vulnerability. These include demographic, life history, genetic, and habitat dynamics factors for past, current, and/or future periods (Pearson et al., 2014; Iverson et al., 2012; Aubry et al., 2011; Thomas et al., 2011; Foden et al., 2013; Rehfeldt et al., 2014).

In this study, we focus on climate suitability as a critical firstorder predictor of climate vulnerability because of its ecological and management relevance. There is a wealth of evidence that plant species have specific tolerances to climate and that their distributions reflect these tolerances (Chapin et al., 2011). Thus, strong inference can be drawn that: (1) viable populations of a tree species are unlikely to develop or persist where climate is unsuitable; (2) existing populations are likely to decline if climate becomes unsuitable; and (3) locations of newly suitable climate may be able to support future viable populations if several other ecological conditions are met. These inferences are highly relevant to management. Whereas, managers cannot manipulate climate over large landscapes, they can manipulate many of the other factors that influence tree population viability including seedling establishment, genetic composition, interactions with other species (e.g., completion, parasitism, disease), disturbances (e.g., fire). In other words, knowledge of climate suitability is a critical filter for deciding where to use management actions to protect, restore, or establish tree populations under climate change. Accordingly, Dawson et al. (2011) suggested that climate suitability analysis is an important initial step in integrated science assessment of biodiversity under climate change, with complementary approaches including use of paleoecological records, ecophysiological and population models, and experimental manipulations. Accordingly, species that were ranked high in this study in potential impact based on climate envelop modeling are candidates for the additional steps that are often more expensive and sometimes higher levels of uncertainty.

\subsection{Management implications and conclusions}

The NPS Intermountain Region and the Northern Region of the USDA Forest Service have initiated climate vulnerability assessments with the Northern Rockies (Whittington et al., 2014, http://adaptationpartners.org/nrap/). As a component of the climate adaptation planning framework adapted by the US DOI (Glick et al., 2011; Stein et al., 2014), the results of this study can serve as measures of potential impact of climate change on tree species and biome types. However, several additional steps can be suggested to refine climate adaptation planning in the GNLCC.

Bioclimate envelop models could be scaled to the GNLCC boundaries and take advantage of local vegetation data sets in addition to the national data set from FIA. For some species, knowledge of genetic variation is sufficient to evaluate the availability of locally adapted strains the species for colonizing newly suitable habitats (Rehfeldt et al., 2014). Bioclimate envelop models would also be improved by considering habitat factors in addition to climate, such as soil type and texture, water balance, and land form. These data are available at $30-\mathrm{m}$ resolutions and models run at this finer spatial scale may increasingly identify micro-refugia important to some tree populations. The newer IPCC CMIP5 GCMs are now available for the region (e.g., http://forest.moscowfsl. wsu.edu/climate/future/details.php) and the subset of these models that have been shown to perform particularly in our region 
could be used in these analyses. Examples of these more refined methods applied in Greater Yellowstone come from Chang et al. (2014) and Piekielek et al. (unpublished data).

Consistent with the framework of Dawson et al. (2011) approaches to vulnerability assessment are needed that go beyond climate suitability. Ecophysiological and population mechanistic models can be used to more realistically simulate tree species demographic response to climate change and resulting changes in disturbance regimes, as well as interactions with pests and competing tree species. Examples of such applications in the Northern Rockies include Hickler et al. (2004) and Keane et al. (2011).

The adaptive capacity component of vulnerability assessment can be derived from expert opinion when quantitative data are not available. Elements of adaptive capacity that have used in such assessment include demographic, life history, genetic, and habitat dynamics factors for past, current, and/or future periods (see Aubry et al., 2011; Thomas et al., 2011; Iverson et al., 2012; Foden et al., 2013; Pearson et al., 2014; Rehfeldt et al., 2014).

Vulnerability assessments that adequately consider exposure, sensitivity, potential impact, and adaptive capacity have high potential to reveal which species and biome types are most at risk, the locations of highest vulnerability, and the underlying causes. This information is vital to developing, evaluating, and implementing management and adaptation strategies for vulnerable elements. For example, the Greater Yellowstone Coordinating Committee Whitebark Pine Subcommittee's (2011) Whitebark pine strategy used available information to elucidate multiple strategies for restoring this species in the GYE. As these strategies are implemented, monitoring efforts can be used to detect early change and to iteratively test and improve the models and modify management approaches.

Management strategies for species deemed most vulnerable should be stratified geographically based on the locations of current and projected suitable habitats and populations. Locations of where populations are present and habitat is projected to remain suitable in the future are obviously high importance and management strategies should be aimed at maintaining the population in these locations. Within locations where populations are present but habitat is projected to become unsuitable, managers may choose to focus on strategies to delay the loss of these populations as long as possible to maintain local ecological function and allow new populations to establish elsewhere. Strategies to facilitate natural colonization on the leading edge of habitat suitability may allow populations to better track changing conditions (Iverson et al., 2004, Bell et al., 2013). Finally, assisted migration is feasible for newly suitable habitats that are more distant from current populations (McLachlan et al., 2007; Hoegh-Guldberg et al., 2008, Gray \& Hamann). Examples of management strategies of each of these types can be found in Heller and Zavaleta (2009) and examples of coordinated management strategies for maintenance and restoration for Whitebark pine can be found in GYCC (2011) and McLane and Aitken (2012).

Resource managers within the Greater Yellowstone PACE will be challenged to maintain subalpine species under future climate, especially Whitebark pine. As reported above, climate suitability for this species is projected to decline dramatically by the end of the century. More recent climate suitability modeling by Chang et al. (2014) (accepted) projected 71-98\% reductions in suitable area by 2100 under RCP 4.5 (similar to SRES B1) and 90-99\% loss under RCP 8.5, with the variation due to differences among GCMs. Adaptive capacity of this species is thought to be relatively low because dispersal is fairly limited, the species is often outcompeted by other subalpine conifers, and the species is highly susceptible to mountain bark beetles and the exotic pine blister rust. Current restoration efforts focus on planting blister rust resistant seedlings, using prescribed fire to facilitation regeneration, and controlling competing species. Motivation to retain Whitebark pine and other conifers in GYE is high because shifts in climate suitability away from conifer communities and toward desert scrub communities would likely have large negative impacts on snowpack, runoff, wildlife, and esthetics.

Tree species projections for the Glacier PACE suggest montane and mesic species will continue to have suitable climate conditions there, even if conditions for subalpine species deteriorate. Assessment and management activities aimed at Whitebark pine are being conducted in and around Glacier National Park. Mountain hemlock response to climate change, however, has received much less attention. This species is abundant in the higher elevation of the Cascade and Coast ranges in the U.S. and British Columbia. It is projected to undergo reduced area of suitable climate in those regions (Crookston et al., Hamann and Wang, 2006) but not the extreme reductions indicated in the GNLCC by our results. These results suggest that additional study is needed for Mountain hemlock on the west side of the Northern Rockies.

Beyond the GNLCC, the methods developed in this study can be applied in other geographic locations to conduct viability assessments based on climate suitability. An example for the Appalachian LCC comes from a companion study by Zolkos et al. (in press). The results of such assessments can help managers prioritize species for more detailed research and climate adaptation planning.

\section{Acknowledgements}

Funding was provided by the NASA Applied Sciences Program (10-BIOCLIM10-0034), and the North Central Climate Sciences Center. We thank the authors of each of the studies included in this synthesis for providing original data. Bill Monahan provided extensive review and suggestions on an earlier draft of the manuscript. The study benefited from discussions with John Gross, Bill Monahan, Tom Olliff, Tony Chang, Nate Piekielek, Patrick Jantz, Dave Theobald, and Virginia Kelly.

\section{Appendix A. Supplementary material}

Supplementary data associated with this article can be found, in the online version, at http://dx.doi.org/10.1016/j.foreco.2014.11. 008.

\section{References}

Allen, C., Macalady, A.K., Chenchouni, H., Bachelet, D., McDowell, N., et al., 2010. A global overview of drought and heat induced tree mortality reveals emerging climate change risks for forests. For. Ecol. Manage. 259, 660-684.

Aubry, C., Devine, W., Shoal, R., Bower, A., Miller, J., Maggiulli, N., 2011. Climate Change and Forest Biodiversity: A Vulnerability Assessment and Action Plan for National Forests in Western Washington. USDA Forest Service, PNW Region, Portland, OR.

Baron, J., 2002. Rocky Mountain Futures: An Ecological Perspective. Island Press, Washington D.C. USA.

Beale, C.M., Lennon, J.J., Gimona, A., 2008. Opening the climate envelope reveals no macroscale associations with climate in European birds. Proc. Natl. Acad. Sci. U.S.A. 105, 14908-14912.

Bell, D.M., Bradford, J.B., Lauenroth, W.K., 2013. Early indicators of change: divergent climate envelopes between tree life stages imply range shifts in the western United States. Glob. Ecol. Biogeogr. 23, 168-180. http://dx.doi.org/ 10.1111/geb.12109.

Bell, D.M., Bradford, J.B., Lauenroth, W.K., 2014. Mountain landscapes offer few opportunities for high-elevation tree species migration. Glob. Change Biol. 20, 1441-1451. http://dx.doi.org/10.1111/gcb.12504.

Berry, P.M., Dawson, T.P., Harrison, P.A., Pearson, R.G., 2002. Modelling potentia impacts of climate change on the bioclimatic envelope of species in Britain and Ireland. Glob. Ecol. Biogeogr. 11, 453-462.

Breshears, D.D., Cobb, N.S., Rich, P.M., Price, K.P., Allen, C.D., et al., 2005. Regional vegetation die-off in response to global-change-type drought. Proc. Natl. Acad. Sci. USA 102, 15144-15148.

Brown, D.E., 1994. Biotic Communities of Southwest U.S. and Northwest Mexico. University of Utah Press, Salt Lake City, Utah, USA. 
Brown, D.E., Reichenbacher, F., Franson, S.E., 1998. A Classification of North American Biotic Communities. University of Utah Press, Salt Lake City, Utah, USA.

Chang, T., Hansen, A.J., Piekielek, N., 2014. Patterns and variability of projected bioclimate habitat for Pinus albicaulis in the Greater Yellowstone Ecosystem. PLOS One.

Chapin III, F. Stuart, Matson, P.A., Vitousek, P.M., 2011. Principles of Terrestrial Ecosystem Ecology, second ed. Springer, New York.

Clark, J.S., Lewis, M., McLachlan, J.S., HilleRisLambers, J., 2003. Estimating population spread: what can we forecast and how well? Ecology 84, 1979-1988.

Cole, K.L., Ironside, K., Eischeid, J., Gargin, G., Duffy, P.B., Toney, C., 2011. Past and ongoing shifts in Joshua tree distribution support future modeled range contraction. Ecol. Appl. 21 (1), 137-149.

Colwell, R., Avery, S., Berger, J., Davis, G.E., Hamilton, H., et al., 2012. Revisiting Leopold: Resource Stewardship in the National Parks. National Park System Advisory Board Science Committee, Washington, D.C., USA.

Coops, N.C., Waring, R.H., 2011. Estimating the vulnerability of fifteen tree species under changing climate in Northwest North America. Ecol. Model. 222, 2119 2129.

Crookston, N.L., Rehfeldt, G.E., Dixon, G.E., Weiskittel, A.R., 2010. Addressing climate change in the forest vegetation simulator to assess impacts on landscape forest dynamics. For. Ecol. Manage. 260, 1198-1211.

Daly, C., Gibson, W.P., Taylor, G.H., Johnson, G.L., Pasteris, P., 2002. A knowledgebased approach to the statistical mapping of climate. Clim. Res. 22, 99-113.

Davis, C.R., Hansen, A.J., 2011. Trajectories in land-use change around U.S. National Parks and their challenges and opportunities for management. Ecol. Appl. 21, 3299-3316.

Davis, M.B., Shaw, R.G., 2001. Range shifts and adaptive responses to Quaternary climate change. Science 292, 673-679.

Dawson, T.P., Jackson, S.T., House, J.I., Prentice, I.C., Mace, G.M., 2011. Beyond predictions: biodiversity conservation in a changing climate. Science 332, 53-58.

Despain, D.G., 1990. Yellowstone Vegetation: Consequences of Environment and History in a Natural Setting. Roberts Reinhart Publishers, Boulder CO.

Foden, W.B., Butchart, S.H.M., Stuart, S.N., Vié, J.C, Akçakaya, H.R., et al. 2013. Identifying the World's most climate change vulnerable species: a systematic trait-based assessment of all birds, amphibians and corals. PLoS ONE 8 (6), e65427. http://dx.doi.org/10.1371/journal.pone.0065427.

Fordham, D.A., Akçakaya, H.R., Araújo, M.B., Elith, J., Keith, D.A., et al., 2012. Plant extinction risk under climate change: are forecast range shifts alone a good indicator of species vulnerability to global warming? Glob. Change Biol. 18, 1357-1371.

Glick, D., Stein, B.A., Edelson, N.A. (Eds.), 2011. Scanning the Conservation Horizon: A Guide to Climate Change Vulnerability Assessment. National Wildlife Federation, Washington, D.C., USA.

Gray, L.K., Hamann, A., 2013. Tracking suitable habitat for tree populations under climate change in western North America. Clim. Change 117, 289-303.

Guisan, A., Thuiller, W., 2005. Predicting species distribution: offering more than simple habitat models. Ecol. Lett. 8, 993-1009, blackwell-synergy.com/doi/abs 10.1111/j.1461-0248.2005.00792.x.

GYCC, 2011. Whitebark Pine Strategy for the Greater Yellowstone Area. Greater Yellowstone Coordinating Committee Whitebark Pine Subcommittee, $41 \mathrm{p}$.

Hamann, A., Wang, T., 2006. Potential effects of climate change on ecosystem and tree species distribution in British Columbia. Ecology 87, 2773-2786.

Heller, N.E., Zavaleta, E.S., 2009. Biodiversity management in the face of climate change: a review of 22 years of recommendations. Biol. Conserv, 142, 14-32.

Hickler, T., Smith, B., Sykes, M.T., Davis, M.B., Sugita, S., Walker, K., 2004. Using a generalized vegetation model to simulate vegetation dynamics in northeastern USA. Ecology 85, 519-530.

Hoegh-Guldberg, O., Hughes, L., McIntyre, S., Lindenmayer, D.B., Parmesan, C., Possingham, H.P., Thomas, C.D., 2008. Assisted colonization and rapid climate change. Science 321, 345-346.

Huntley, B., Berry, P.M., Cramer, W., Mcdonald, A.P., 1995. Modelling present and potential future ranges of some European higher plants using climate response surfaces. J. Biogeogr. 22, 967-1001.

IPCC, 2001. Summary for Policymakers: Emissions Scenarios. Special Report of IPCC Working Group III. ISBN: 92-9169-113-5.

IPCC, 2007. Climate Change 2007: Synthesis Report. In: Contribution of Working Groups I, II, and III to the Fourth Assessment Report of the Intergovernmental Panel on Climate Change. Integovernmental Panel on Climate Change, Geneva, Switzerland.

Iverson, L.R., Schwartz, M.W., Prasad, A.M., 2004. How fast and far might tree species migrate in the eastern United States due to climate change? Glob. Ecol. Biogeogr. 13, 209-219.

Iverson, L.R., Matthews, S.N., Prasad, A.M., Peters, M.P., Yohe, G., 2012. Development of risk matrices for evaluating climatic change responses of forested habitats. Clim. Change 114, 231-243.

Jiang, X., Rauscher, S.A., Ringler, T.D., Lawrence, D.M., Williams, A.P., et al., 2013. Projected future changes in vegetation in western North America in the Twenty-First Century. Am. Meteorol. Soc. 26, 3671-3687. http://dx.doi.org/ 10.1175/JCLI-D-12-00430.1.

Karl, T.R., Melillo, J.M., Peterson, T.C. (Eds.), 2009. Global Climate Change Impacts in the United States. Cambridge University Press.

Keane, R.E., Loehman, R.A., Holsinger, L.M., 2011. The FireBGCv2 landscape fire succession model: a research simulation platform for exploring fire and vegetation dynamics. In: United States Department of Agriculture, Forest Service, Rocky Mountain Research Station, General Technical Report-255. Fort Collins CO.
Loarie, S.R., Carter, B.E., Hayhoe, K., McMahon, S., Moe, R., et al., 2008. Climate Change and the future of California's Endemic Flora. PLoS ONE 3 (6), e2502. http://dx.doi.org/10.1371/journal.pone.0002502.

Logan, J.A., Macfarlane, W.W., Willcox, L., 2010. Whitebark pine vulnerability to climate-driven mountain pine beetle disturbance in the Greater Yellowstone Ecosystem. Ecol. Appl. 20, 895-902.

McKinney, D.W., Pedlar, J.H., Rood, R.B., Price, D., 2011. Revisiting projected shifts in the climate envelopes of North American trees using updated general circulation models. Glob. Change Biol. 17, 2720-2730.

McLachlan, J.S., Hellmann, J.J., Schwartz, M.W., 2007. A framework for debate of assisted migration in an era of climate change. Conserv. Biol. 21, 297-302.

McLane, S.C., Aitken, S.N., 2012. Whitebark pine (Pinus albicaulis) assisted migration potential: testing establishment north of the species range. Ecol. Appl. 22, 142 153.

Mote, P., Salathe, E., Duliere, V., Jump, E., 2008. Scenarios of future climate for the Pacific Northwest, 2008 report from the Climate Impacts Group, University of Washington.

Mote, P.W., Abatzoglou, J.T., Kunkel, K.E., 2013. Climate variability and change in the past and the future. In: Dalton, M.M., Mote, P.W., Snover, A.K. (Eds.), Climate Change in the Northwest: Implications for Our Landscapes, Waters, and Communities. Island Press, Washington, D.C., pp. 25-37.

National Park Service, 2010. National Park Service Climate Change Response Strategy. National Park Service Climate Change Response Program, Fort Collins, Colorado, USA.

Notaro, M., Mauss, A., Williams, J.W., 2012. Projected vegetation changes for the American Southwest: combined dynamic modeling and bioclimatic-envelope approach. Ecol. Appl. 22, 1365-1388.

Pearson, R.G., Dawson, T.P., 2003. Predicting the impacts of climate change on the distribution of species: are bioclimate envelope models useful? Global Ecol. Biogeogr. 12, 361-371, http://doi.wiley.com/10.1046/j. 1466-822X.2003. 00042.x..

Pearson, R.G., Stanton, J.C., Shoemaker, K.T., Aiello-Lammens, M.E., Ersts, P.J., et al., 2014. Life history and spatial traits predict extinction risk due to climate change. Nat. Clim. Change 4, 217-221.

Rehfeldt, G.E., 2006. A spline climate model for western United States. In: General Technical Report 165. USDA, Forest Service, Rocky Mountain Research Station, Fort Collins, Colorado, USA.

Rehfeldt, G.E., Crookston, N.L., Saenz-Romero, C., Cambell, E.M., 2012. North American vegetation model for land-use planning in a changing climate: a solution to large classification problems. Ecol. Appl. 22, 119-141.

Rehfeldt, G.E. et al., 2014. Comparative genetic responses to climate in the varieties of Pinus ponderosa and Pseudotsuga menziesii: Clines in growth potential. For. Ecol. Manage. 324, 138-146.

Rogelj, J., Meinshausen, M., Knutti, R., 2012. Global warming under old and new scenarios using IPCC climate sensitivity range estimates. Nat. Clim. Change 2, $248-253$.

Schwartz, M.W., 1993. Modelling effects of habitat fragmentation on the ability of trees to respond to climatic warming. Biodivers. Conserv. 2, 51-61.

Serra-Diaz, J.M., Franklin, J., Ninyerola, M., Davis, F.W., Syphard, A.D., et al., 2013. Bioclimatic velocity: the pace of species exposure to climate change. Divers. Distrib., 1-12.

Stein, B.A., Glick, P., Edelson, N., Staudt, A. (Eds.), 2014. Climate-Smart Conservation: Putting Adaptation Principles into Practice. National Wildlife Federation, Washington, D.C.

Theobald, D.M., 2014. Development and applications of a comprehensive land use classification and map for the US. PLoS ONE. http://dx.doi.org/10.1371/ journal.pone.0094628.

Thomas, C.D., Cameron, A., Green, R.E., Bakkenes, M., Beaumont, L.J., et al., 2004 Extinction risk from climate change. Nature 427, 145-148, http:// www.ncbi.nlm.nih.gov/pubmed/14712274

Thomas, C.D., Hill, J.K., Anderson, B.J., Bailey, S., Beale, C.M., et al., 2011. A framework for assessing threats and benefits to species responding to climate change. Methods Ecol. Evol. 2, 125-142. http://dx.doi.org/10.1111/j.2041-210X.2010.00065.x.

Thuiller, W., Lavorel, S., Araújo, M.B., Sykes, M.T., Prentice, I.C., 2005. Climate change threats to plant diversity in Europe. Proc. Natl Acad. Sci. 102, 82458250.

U.S. Department of the Interior, 2009. Secretarial Order 3289. Addressing the Impacts of Climate Change on America's Water, Land, and Other Natural and Cultural Resources. U.S. Department of the Interior, Washington, D.C., USA.

USDA Forest Service, 2003. USFS Inventoried Roadless Areas for Contiguous US. USDA Forest Service Geospatial Service and Technology Center, Salt Lake City, UT.

U.S. Geologic Survey, 1997. Federal and Indian Land Features of the US Nevada Bureau of Mines and Geology. University of Nevada, Reno, NV.

Westerling, A.L., Hidalgo, H.G., Cayan, D.R., Swetnam, T.W., 2006. Warming and earlier spring increase western US forest wildfire activity. Science 313, 940-943.

Whittington, T., Olliff, S.T., Benjamin, P. (Eds.), 2014. Climate Change Action Plan Report: Intermountain Region. National Park Service, Lakewood, Colorado.

Wiken, E., Jiménez Nava, Francisco, Griffith, Glenn, 2011. North American Terrestrial Ecoregions-Level III. Commission for Environmental Cooperation, Montreal, Canada.

Zhu, K., Woodall, C.W., Clark, J.S., 2012. Failure to migrate: lack of tree range expansion in response to climate change. Glob. Change Biol. 18, 1042-1052.

Zolkos, S.G., Jantz, P., Cormier, T., Iverson, L., McKenney, D., Goetz, S.J., in press. Projected tree species redistribution under climate change: implications for ecosystem vulnerability across protected areas in the eastern United States. J. Biogeogr. 